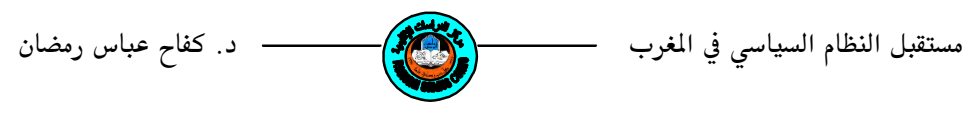

$$
\begin{aligned}
& \text { مستقبل الذظام السياسي في المغرب العربي، الجزائر أنموذجاً } \\
& \text { د. دفاح عباس رمضان } \\
& \text { مدرس/ قسم الدراسات التاريخية والثقافية/ مركز الدراسات الإقليمية }
\end{aligned}
$$

$$
\text { مستخلص البحث }
$$

مذذ أوائل التسعينات من القرن المنصرم تسيطر حالة من عدم اليقين بشأن مستقبل النظـام السياسي في المغرب العربي في ظل التحولات الدولية والإقليمية الجارية. والتي بدأت مسع نهايـة الحسب البـاردة على المستوى الدولي، ونهاية حرب الخليج على المستوى العربي، وظهور الحركات الإسلامية في المغرب

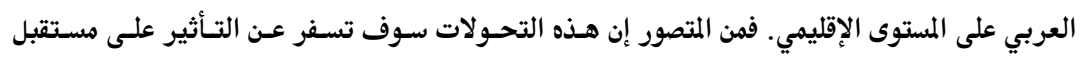
النظام في المغرب العربي في المرحلة القادمة.

وتعد التجربة الجزائرية رائدة على مستوى العـالم الثالـث بصسورة عامسة والـوطن العربي بصسورة خاصة، من حيث العبر التي يمكن استخلاصها من آثار ممارساتها للديمقراطية السلبية والايجابية. لـذا سلطنا الضوء في هذا البحث على مسار النظام الديمقراطي في الجزائر في عهد الرئيس عبدالعزيز بوتفليقة منذ اعتلائه سـدة الحكـم عـام 1999، وإلى حـد الآن، لمـا تتمتـع بهـا التجربـة الجزائريـة مـن ميـزات وتحديات داخلية وخارجية على حد سواء.

المقدمة

مذذ منتصف عام 1991 تسيطر حالة من عدم اليقين بشأن مستقبل النظسام السياسسي في

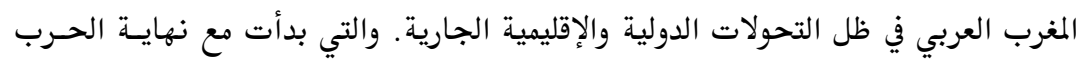
الباردة على المستوى الدولي، ونهاية حرب الخليج على المستوى العربي، وظهور الحركـات الإسلامية في المغرب العربي على المستوى الإقليمي. فمن المتصسور إن هـذه التحـولات سـوف تسفر عن التأثير على مستقبل النظام في المغرب العربي في المرحلة القادمة. اتسـم عـام 2009 في المغـرب العربسي بـالتغيير والإصـلاح، شمـل بالخصـوص البعـدين السياسي والاقتصادي. ويمكن القول إن حدث الانتخابات الرئاسية شكل أحد أهم العناوين، 
وذلك في كل من موريتانيا وتونس والجزائر. فلقـد جـرت انتخابـات رئاسية في هـذه الدول

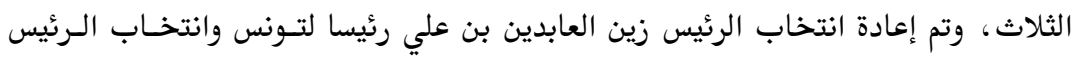

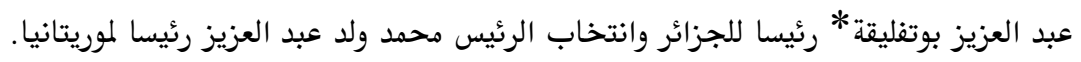

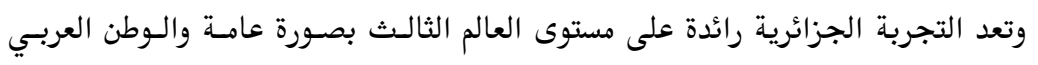

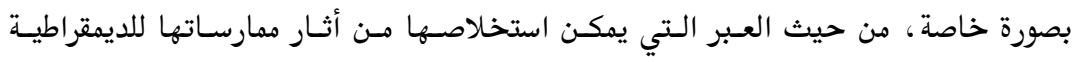

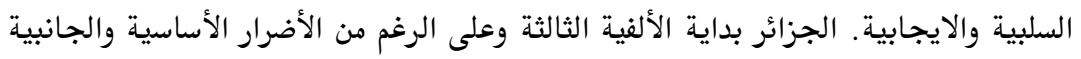

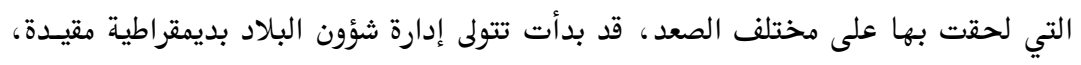

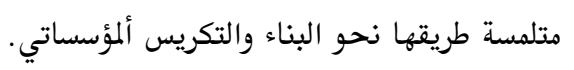
لذا سنسلط الضوء في هذا البحث على مسار النظام الديمقراطي في الجزائر في عهد الرئيس

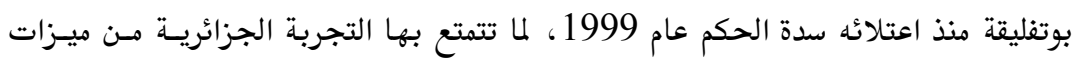

$$
\text { وتحديات داخلية وخارجية على حد سواء. }
$$

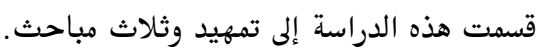
تناول التمهيد تطور الأوضاع السياسية في الجزائر منذ الاستقلال عام 1962 وديد وحتى فـترة

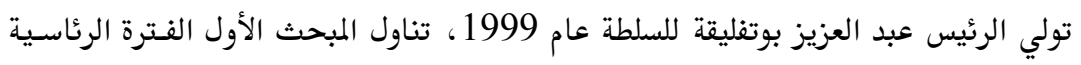

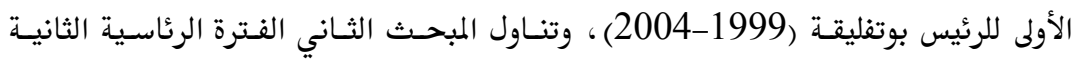

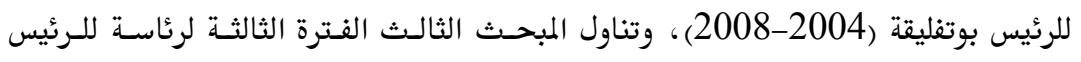
بوتفليقة إلى انتخابات الرئاسية التي جرت في نيسان/ ابريل من عام 2009.

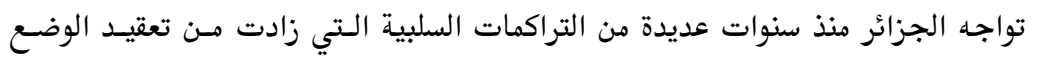

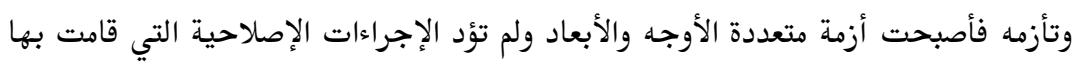
السلطة الحاكمة من اجل تجاوزها وتخطيها أي نتيجة تذكر.

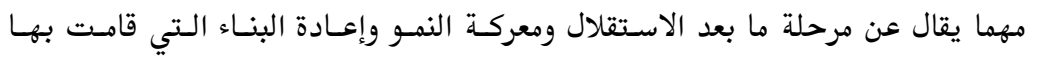

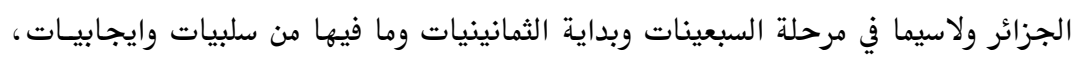




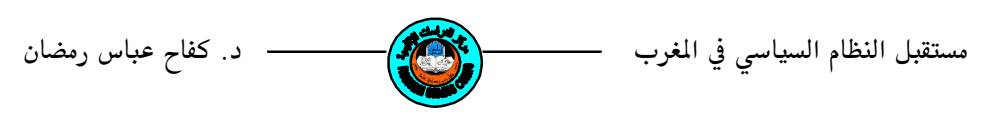

فأن الجزائر استطاعت في وقت قصير إن توفر للمواطن الحد الـذي يضسمن لـه حيـاة كريمـة

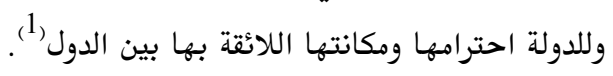
لقد كانت فترة الرئيس هواري بومدين (1965-1978) في تاريخ الجزائر فـترة التشـديد

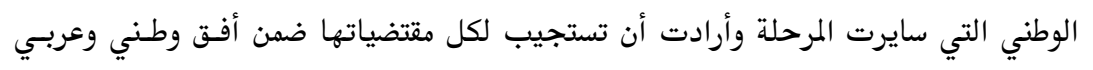

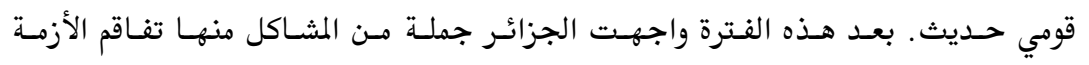

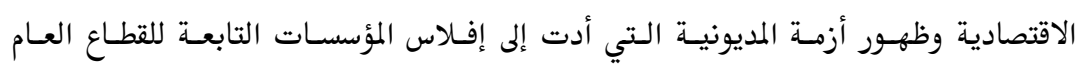

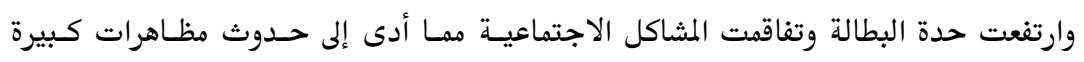

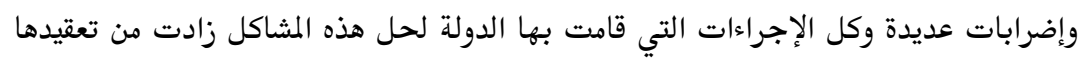

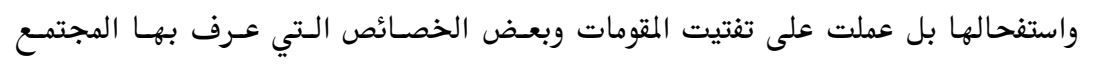

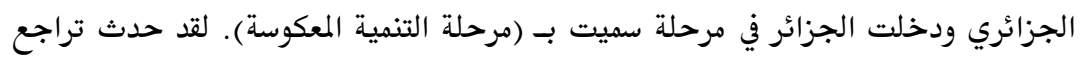

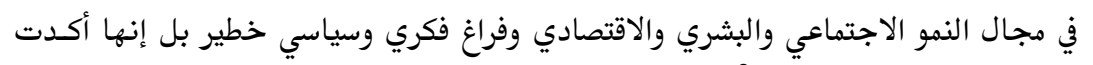
إنها مشكلة غير قابلة للحل ف2.2.

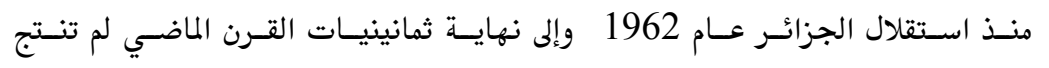

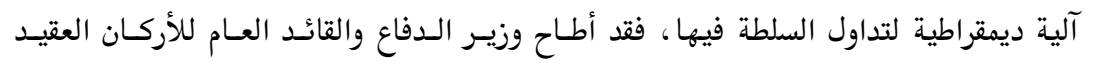

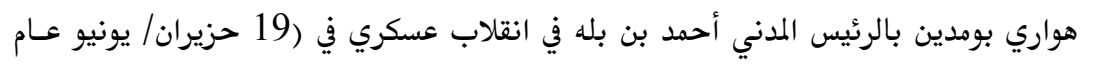

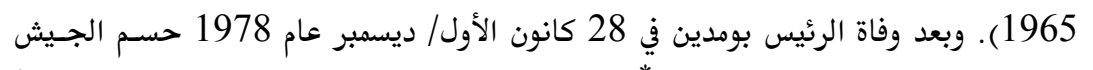
أمر الرئاسة للعقيد الشاذلي بن جديد * الذي كان المرشح الوحيد (باعتباره الضابط الأكبر سناً

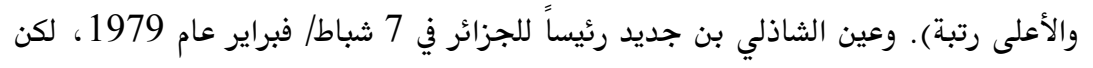

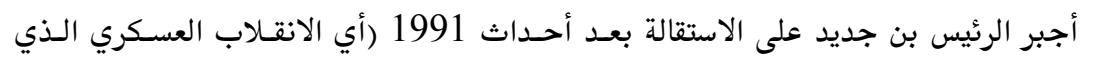

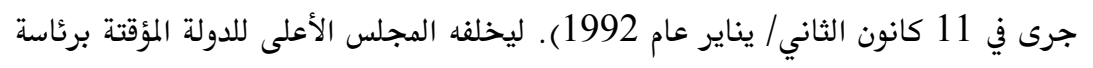

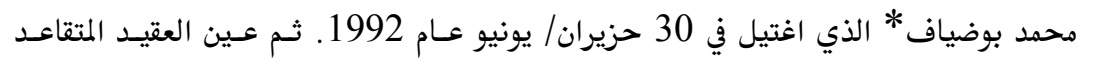

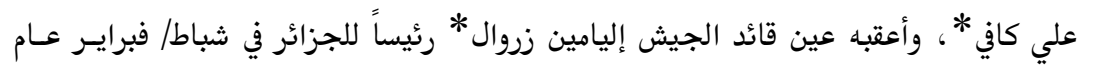

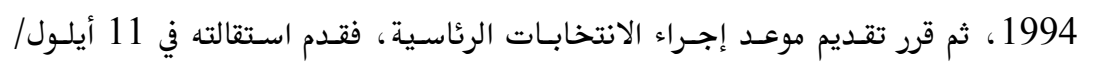

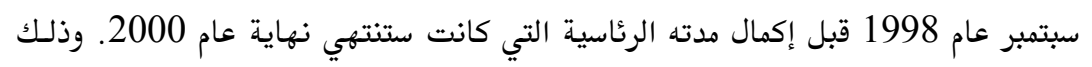


بسبب عدم قدرته على وقف الانهيار الاقتصادي الخطير الذي كان يحدث آنذاك في الجزائر

\section{المبحث الأول: ولاية الرئيس عبدالعزيز بوتفليقة الأولى (1999- 2004)}

جرت انتخابـات رئاسية مبكـرة في الجزائر بسـبب استقالة الـرئيس زروال. ففيدي 15

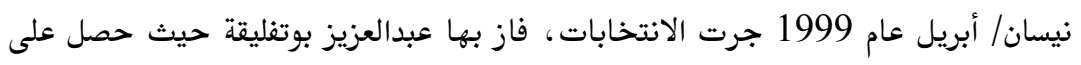

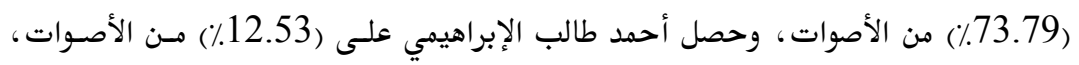

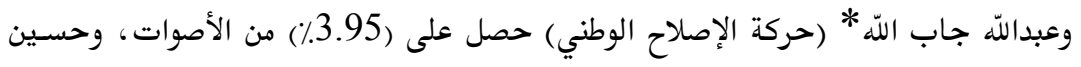

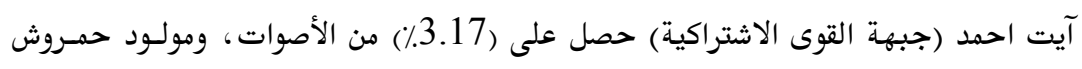

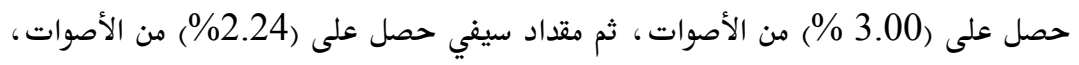

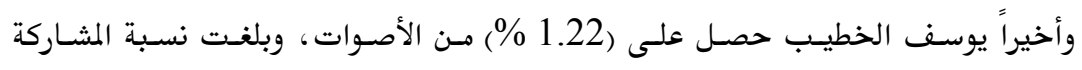

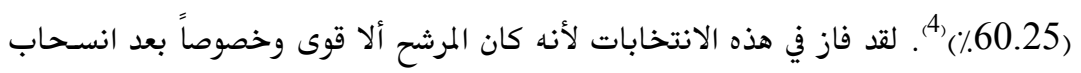

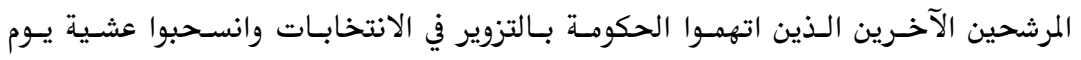

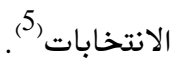
أكد الرئيس بوتفليقـة في خطابـه الأول بعسد انتخابسه عزمسه على تسـوية الملف الأمسني

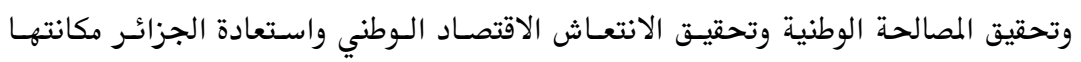
الإقليمية والدولية.6.). كان برنامجه يسعى إلى تحقيـق الأهـداف التاليـة (اسـتباب الأمسن، وإنعـاش الاقتصـاد

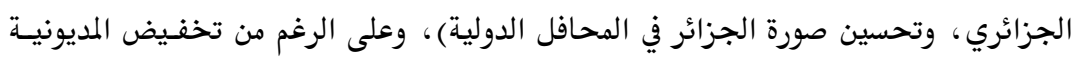

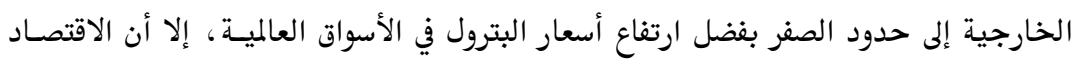

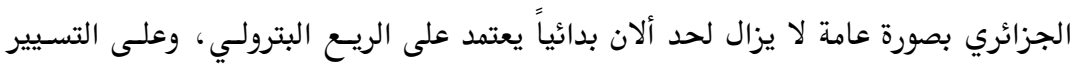

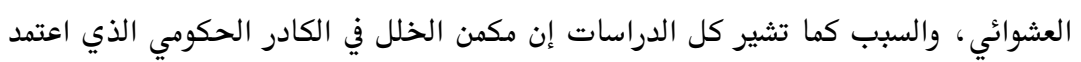

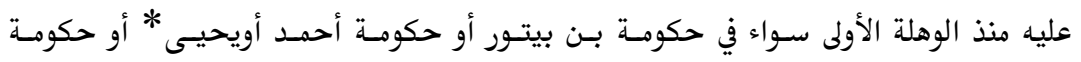
عبدالعزيز بلخادم التي لم يطرأ عليها أي تغيير (7). 


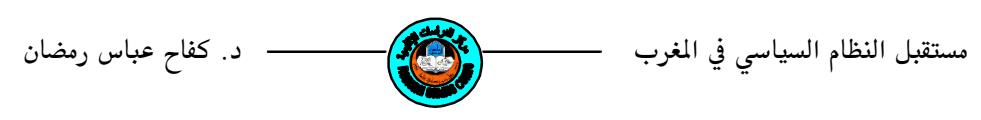

أجرى الرئيس بوتفليقة في 5 حزيران/ يونيو عام 1999، حوار مسع الجبهـة الإسـلامية

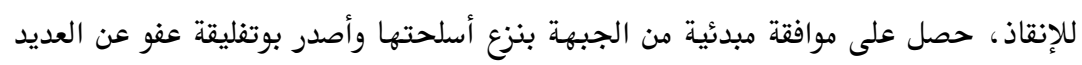

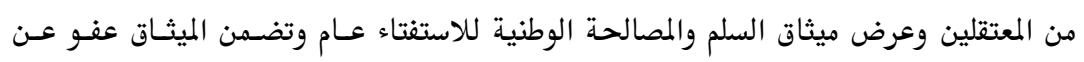

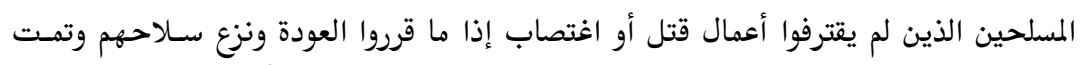

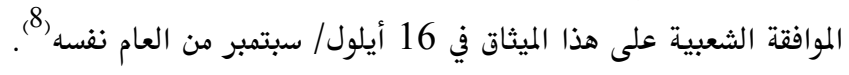

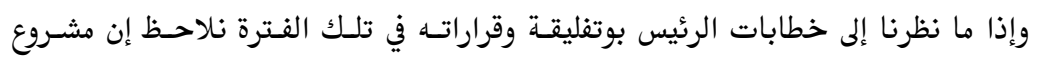

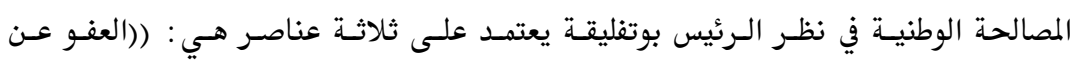

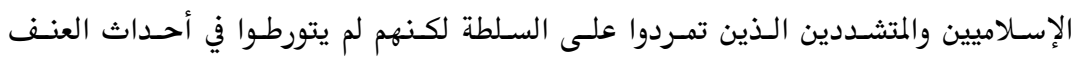

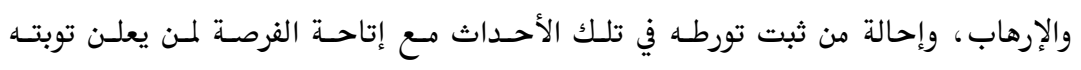

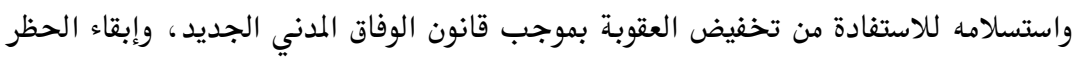

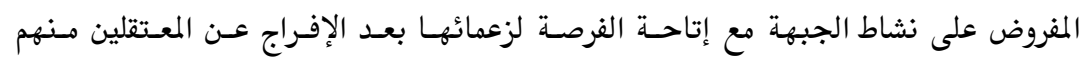

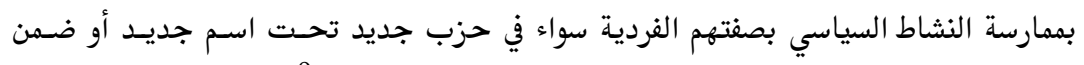
أحزاب إسلامية أخرى شرط أن يلتزم هؤلاء بالدستور وبالقوانين)) (9) . اتخذ الرئيس بوتفليقة العديد من الخطوات الايجابية لتحسين الأوضاع الداخلية، فني 5

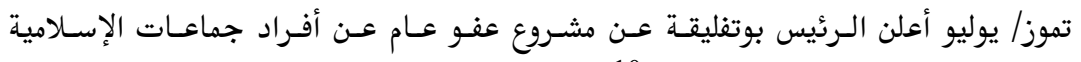

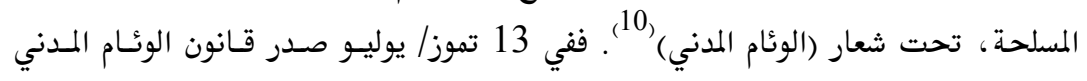

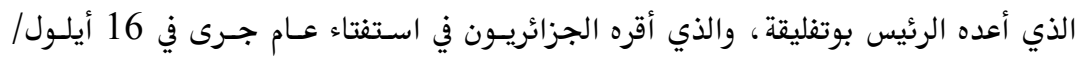

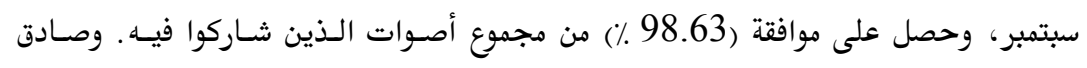

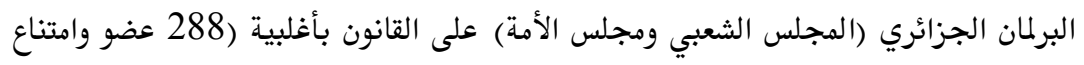

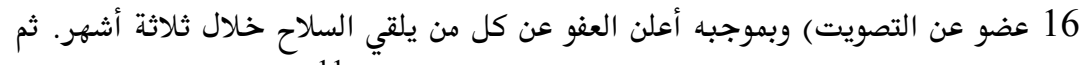

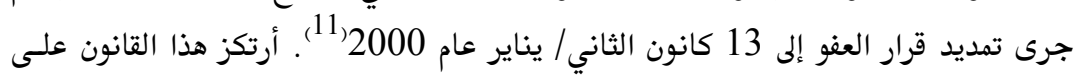

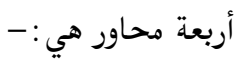
1- التمسك بالدستور والحرص على تنفيذ القوانين. 2- ضمان حقوق ضحايا عام 2002، والتكفل بهم. 3- العرفان إزاء المؤسسات وجميع ضحايا إمان المواطنين الذين كان لهم دور في (إنقاذ) البلاد. 


$$
\text { 4- فسح المجال لعودة كل من ضل الطريق لسبب أو لآخر(12). }
$$

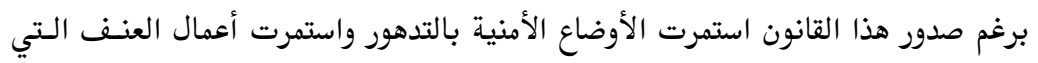

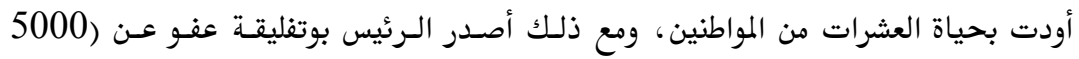

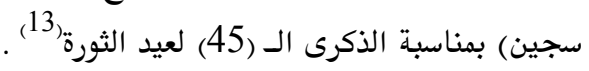

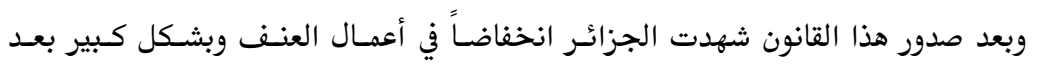
صدور هذا القانون. لأنه حفز أعداد كبيرة من المقاتلين المسلحين إلى إلقاء السلاح والعهودة إلى إلى

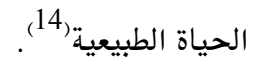

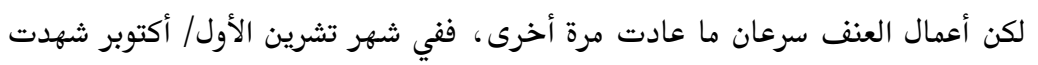

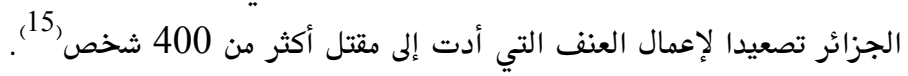

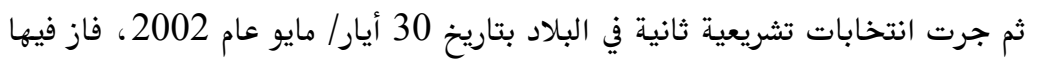

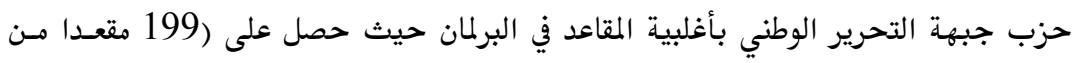

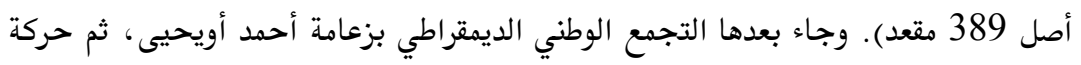

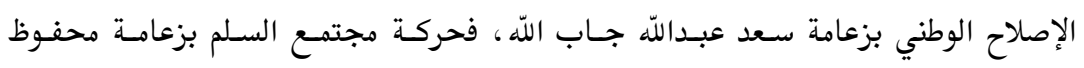

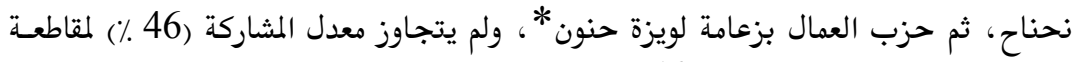
منطقة القبائل في هذه الانتخابات (16).

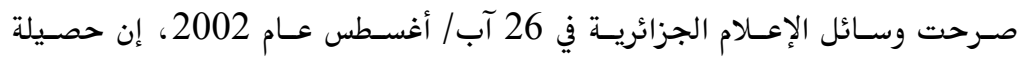
الإعمال المسلحة هي (أكثر من 300 جزائري قتيل)، خلال الأشهر الثلاثة الأخيرة السـابقة

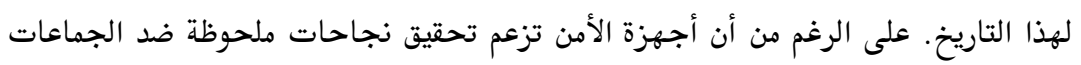

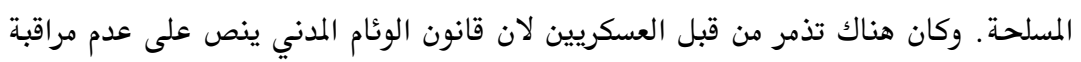

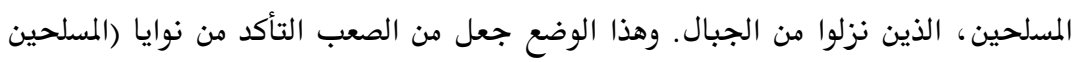

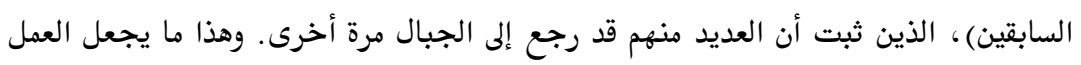
الأمني صعباً للغاية(17). رغم ذلك جرت انتخابات محلية لاختيار أعضاء المجالس الشعبية المحلية في البلديات

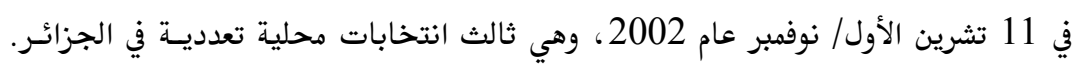




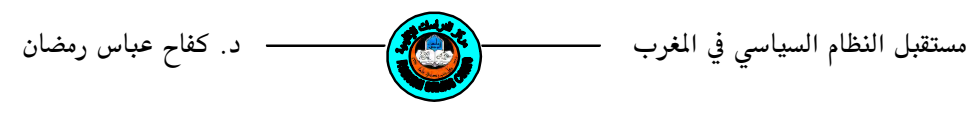

وشارك (24 حزب سياسي) في هذه الانتخابات، والتي قاطعها كل من حسب التجمسع مسن أجل الثقافة والديمقراطية والتحالف الوطني الجمهوري والحركة الديمقراطية الاجتماعية وفاز

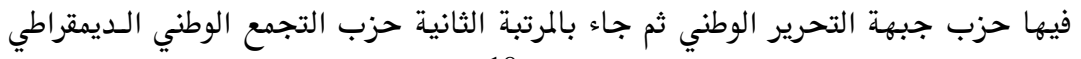
ثم جاءت حركة الإصلاح الوطني بالمرتبة الثالثة(18).

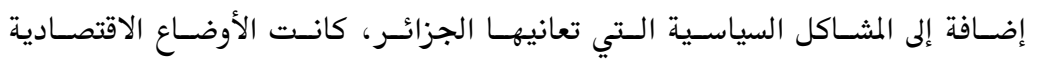

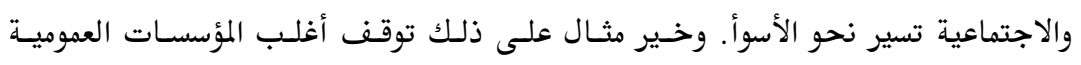

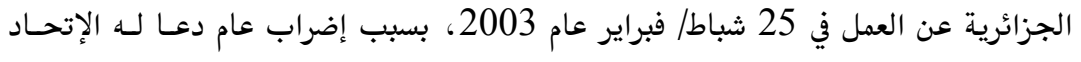

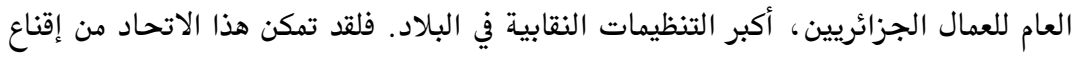

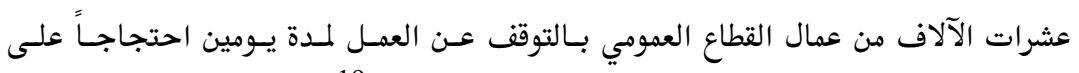
خصخصة القطاع العمومي وسوء الأحوال المعيشية للجزائريين (19).

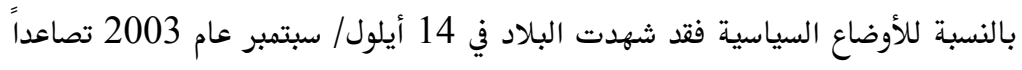

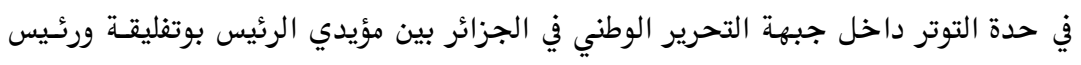

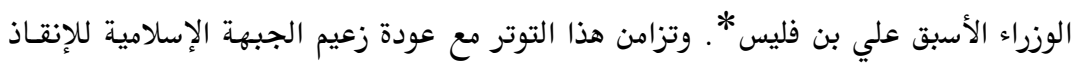

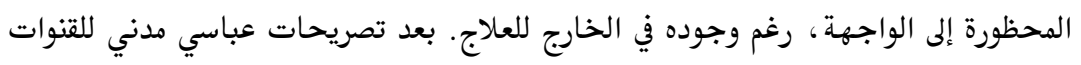

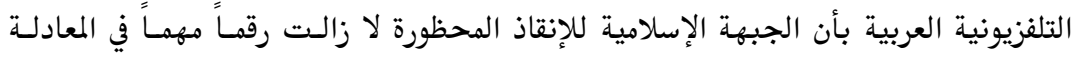
السياسية الجزائرية.20.

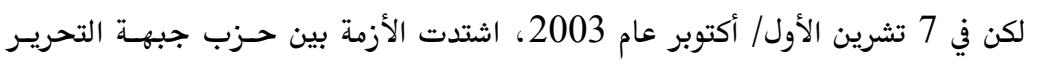

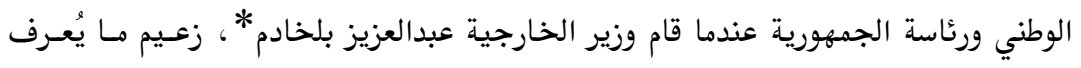

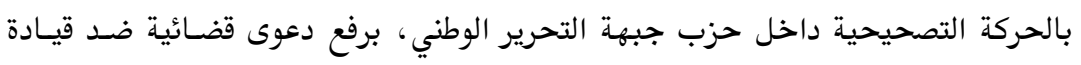

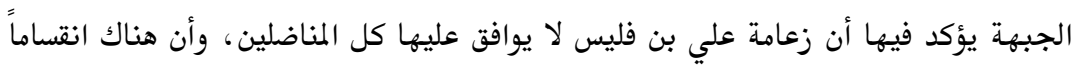

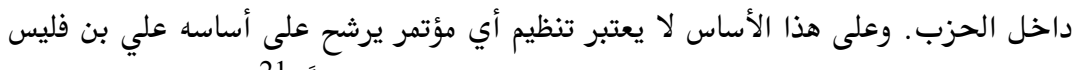
باسم جبهة التحرير في الانتخابات الرئاسية بعد ستة أشهر(شرعياً) (21).

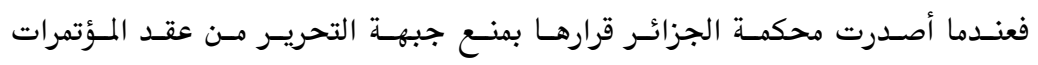

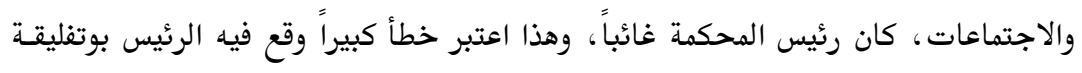

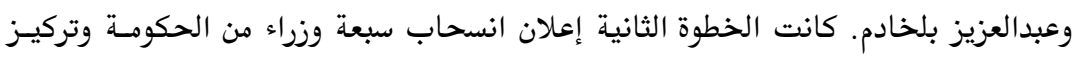


كل جهود جبهة التحرير في الحرب الطاحنة داخل البرلمان والعمـل على ضسمان الاستقرار داخل الحزب).22. (22.

ثم جرى دعوة مندوبي الجبهة في الولايات الجزائرية الثمانية والأربعسين بأقصى سـرعة

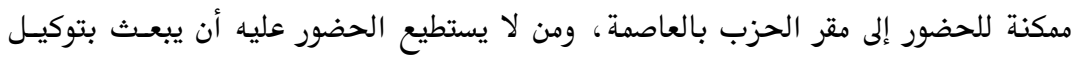

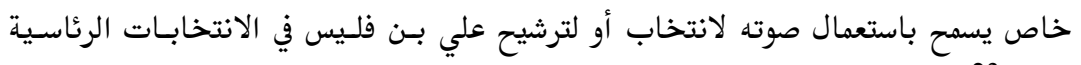

ولقد اندهش المحللون السياسيون أمام سرعة تحضير لقاء المندوبين والمناضـلين، وعنـدما

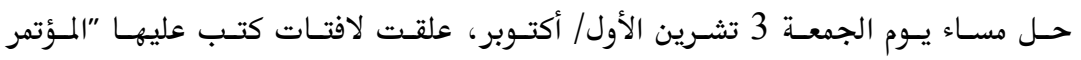

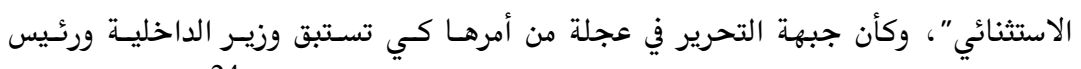

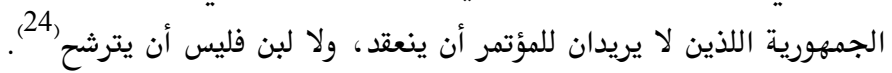

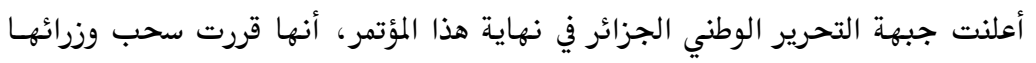

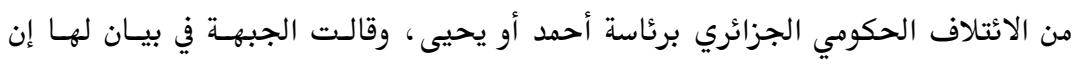

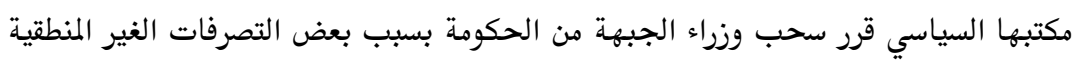

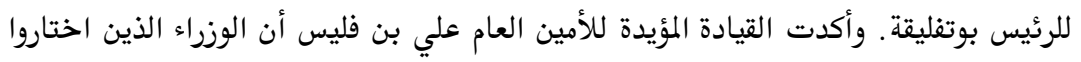

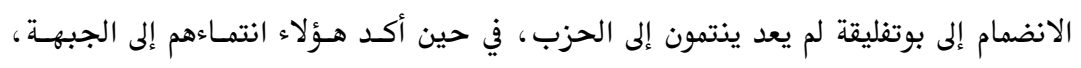

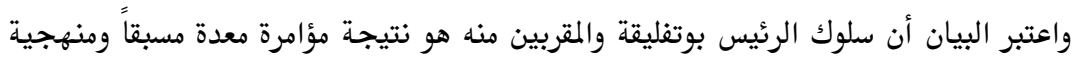

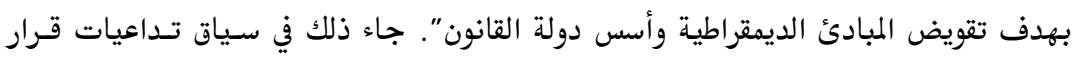

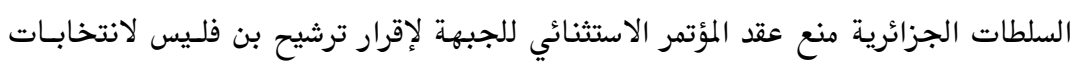

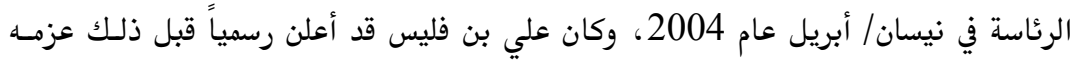

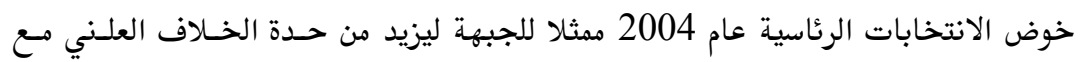
الرئيس بوتفليقة (25).

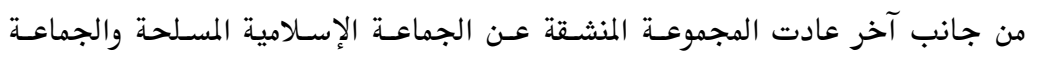

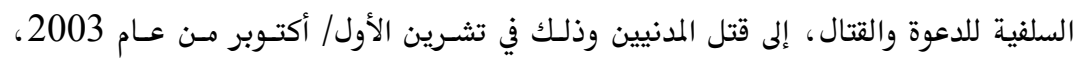



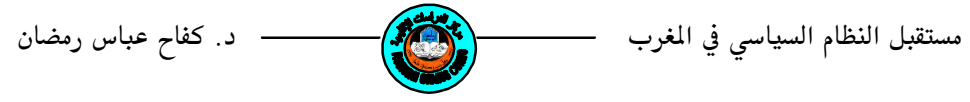

وأيدت علنا تنظيم القاعدة، ورفضت الجماعة السلفية قرار العفو واستمرت في القتـال على الرغم من العديد من أفراد هذه الجماعة قد استسلموال26.

المبحث الثاني: ولاية الرئيس عبدالعزيز بوتفليقة الثانية (2004- 2008)

قبل انتخابات عام 2004، ورغم أن الرئيس بوتفليقة لم يعلن بنوداً تفصيلية لمشسروعه

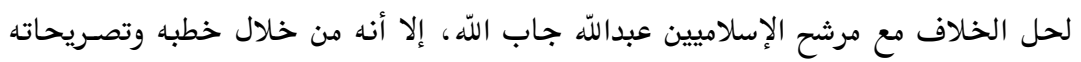

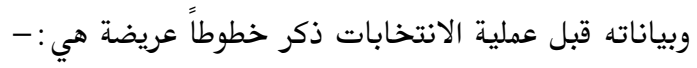

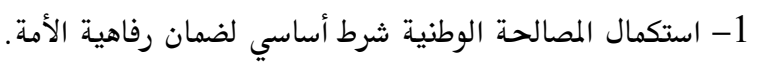
2- المصالحة الوطنية جاءت للقضاء على الفتنة التي أشعلها أعداء الوحدة الوطنية.

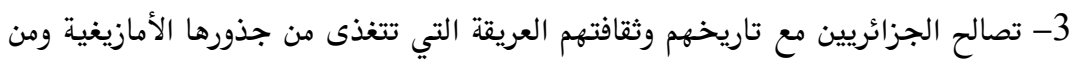
رصيدها العربي والإسلامي.

4- بناء دولة قوية تقوم أركانها على العدل واحترام حقوق الإنسان.

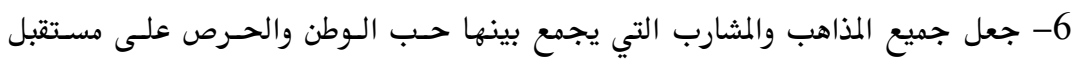

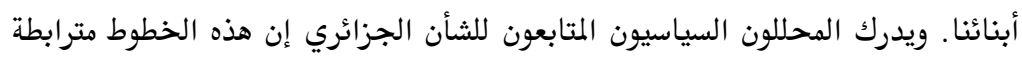

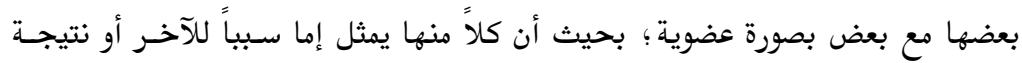
له (27). وفي غضون سنوات الحكم الأولى للرئيس بوتفليقة (1999-2003) عمد الرئيس بوتفليقـة

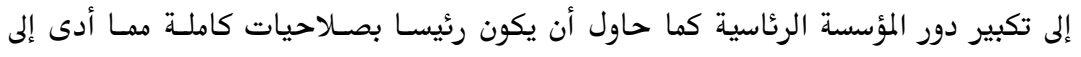
حدوث صدامات بين الرئيس بوتفليقة وكبار السياسيين لذلك عمد هؤلاء إلى دعسم بـن فلـيس

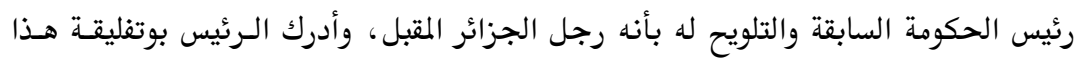

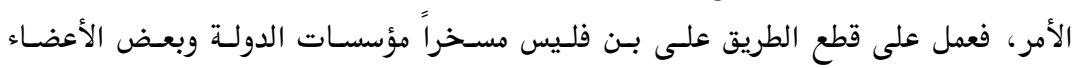
البارزين من داخل حزب جبهة التحرير الوطني (28).

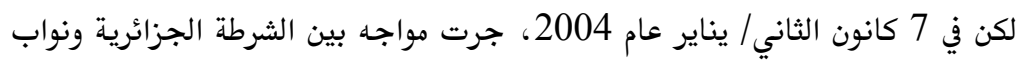

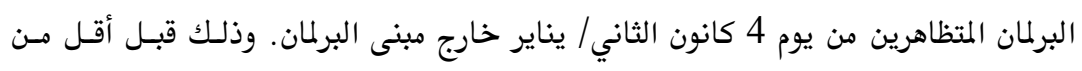


ثلاثة أشهر عن موعد الانتخابات الرئاسية، وعاشت الجزائسر اسـتقطاباً سياسياً حـاداً بـين

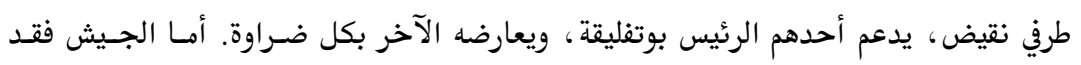

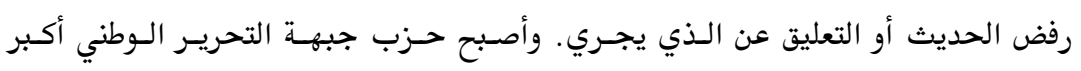

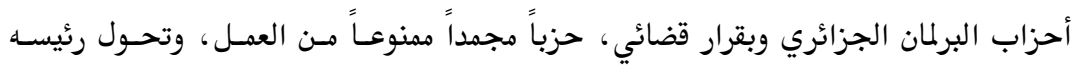

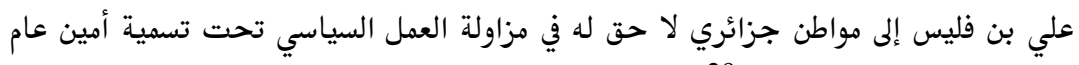
حزب جبهة التحرير الوطني (29). وبرغم ذلك فان المنافسة في الانتخابات كانت قوية ، فلقـد أكـد المحللون السياسيون في 24 شباط/ فبراير عام 2004، بان هنالك ست مرشحين يتنافسون ضد الكد الرئيس بوتفليقـة.

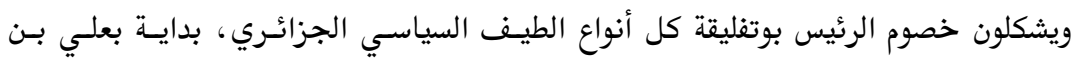

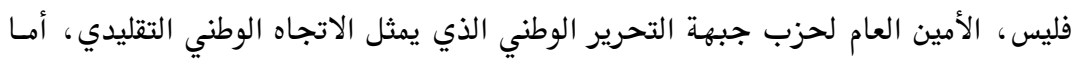

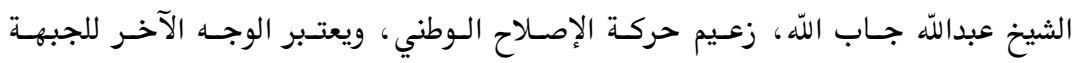

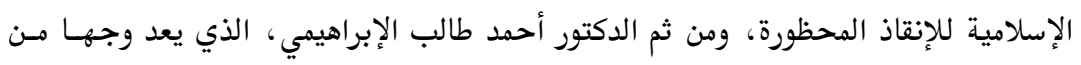

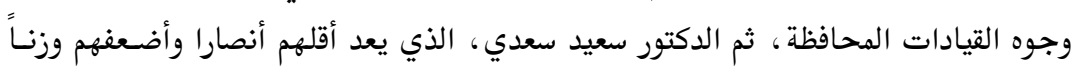

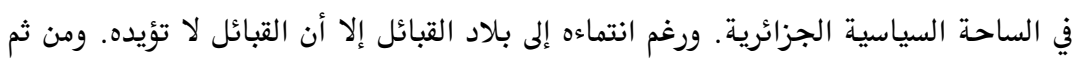

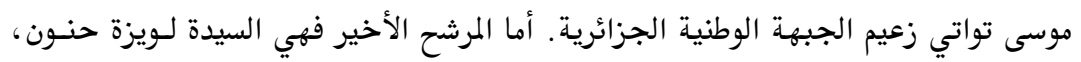
زعيمة حزب العمال اليساري المتشدد (30.).

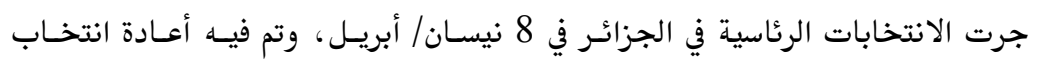

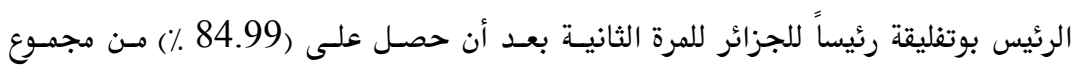

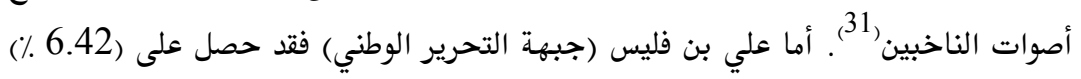

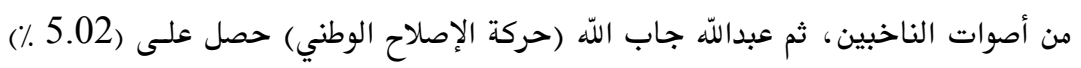

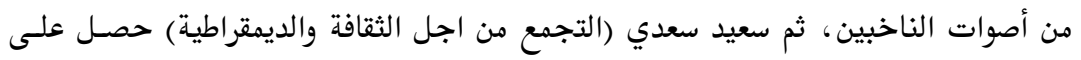

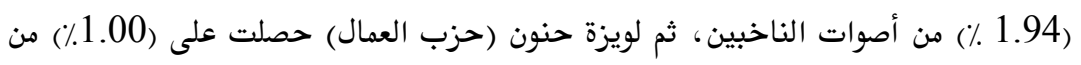

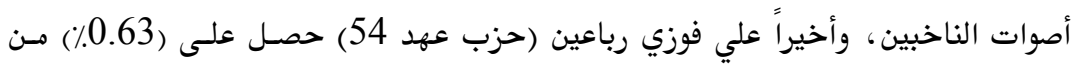

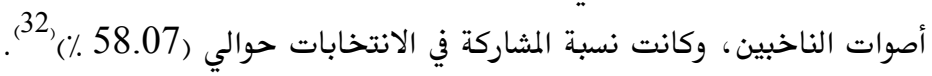




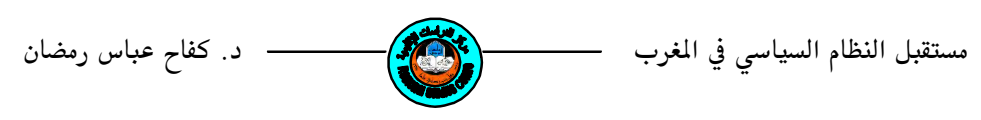

بعد ذلك حاول الرئيس بوتفليقة خلال ولايته الثانية إيجاد مخرج من التدهور السياسي

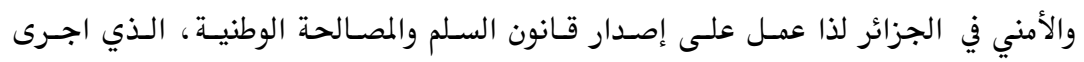

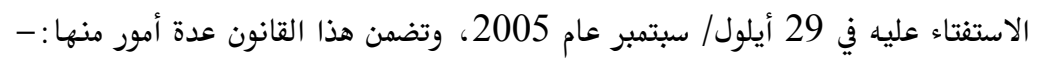

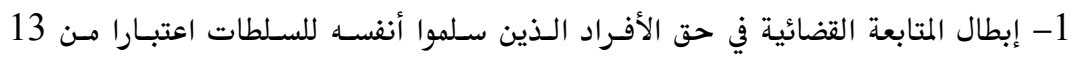

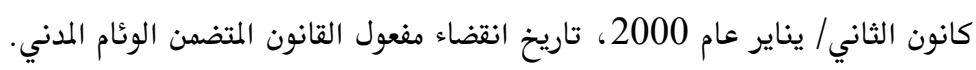

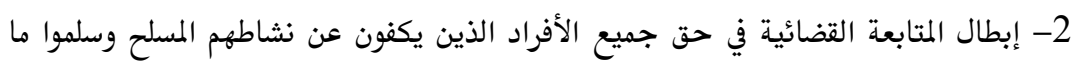

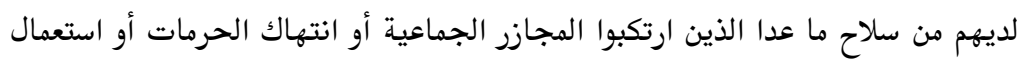
المتفجرات في الأماكن العمومية. 3- إبطال المتابعة القضائية في حق الأفراد المطلوبين داخل الوطن وخارجه ما عدا المستثنين سابقاً.

$$
\text { 5- 5- عودة المفصولون من مناصبهم نتيجة مواقفهم السياسية. }
$$

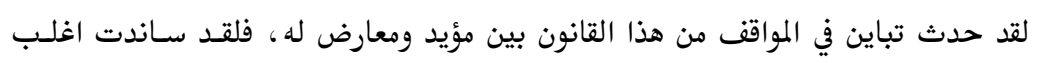

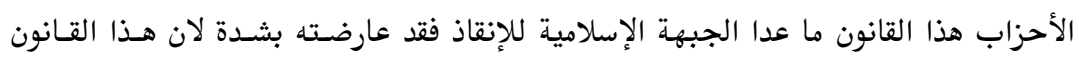
يمنع عودة الجبهة إلى النشاط السياسي (34). من جانب آخر حاول الرئيس بوتغليقة أن يحد من تدهور الأوضاع الاقتصـادية. وحـاول

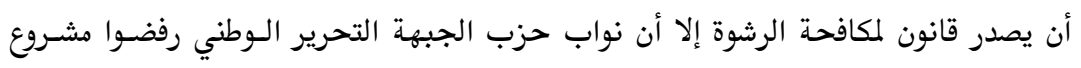

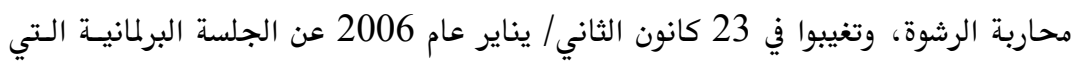

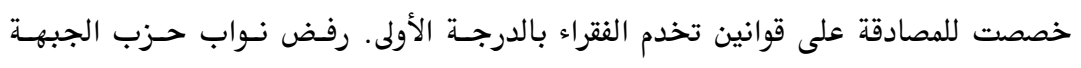

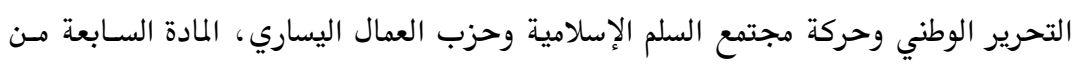

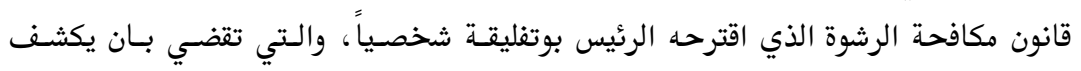

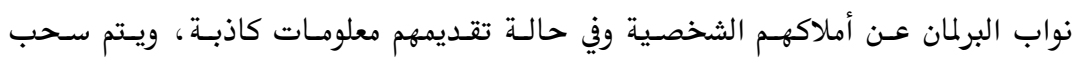

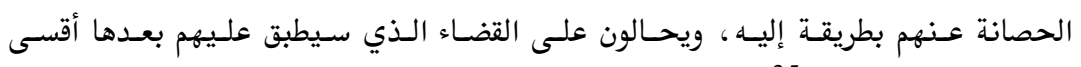
العقوبات المالية وغيرها (35). 
من التغييرات السياسية التي قام بها الرئيس بوتفليقة، إعلانه إجراء تعديل دستوري من

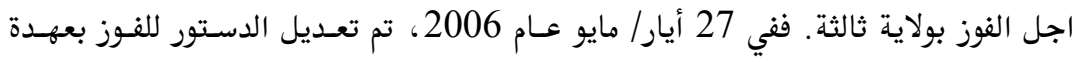

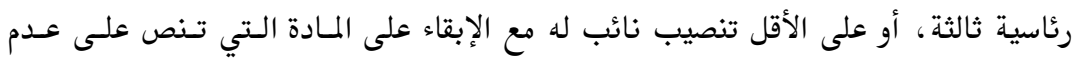

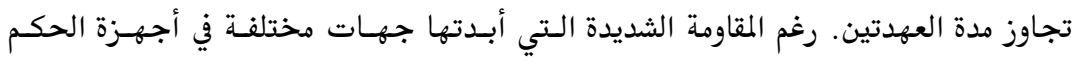

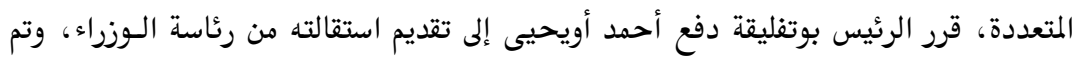

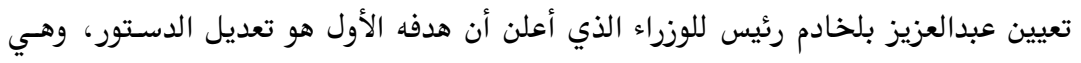

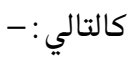
الأول: أن يتمكن الرئيس بوتغليقة من تعديل الدستور وجعل المدد الرئاسية ثلاثا، مـدة كل

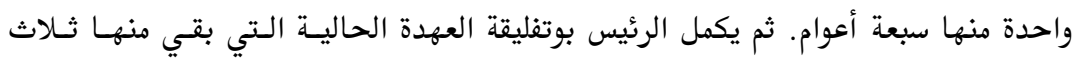
سنوات وبعدها يتولى أمر البلاد لسبع سنوات أخرى.

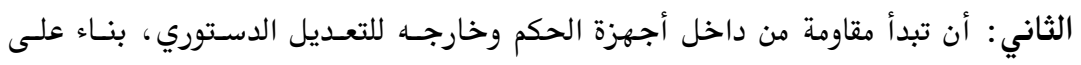
مخاطره المهددة للسلم المدني والتناسق الوطني.

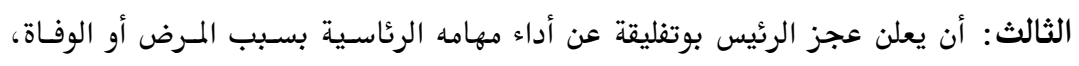
ويخلفه نائبه الذي يعينه. الرابع: أن ينتظر خصوم الرئيس بوتغليقة تطور حالته الصحية التي يعلمون مدى خطورتها، ئنيا،

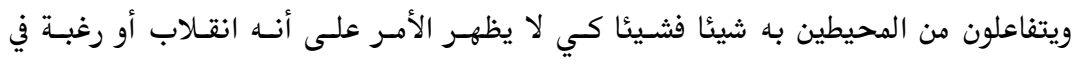

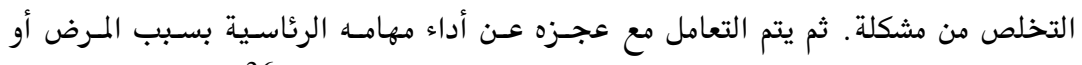

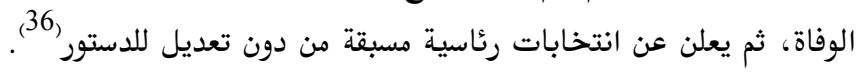

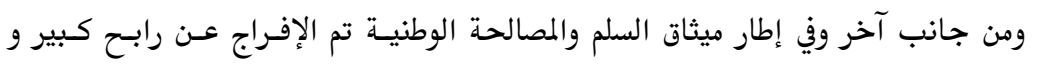

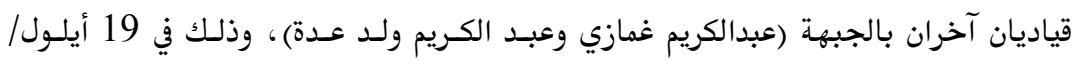

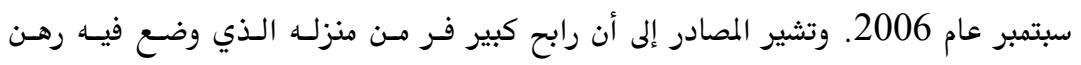

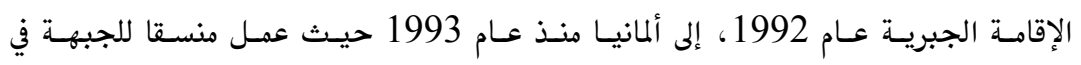

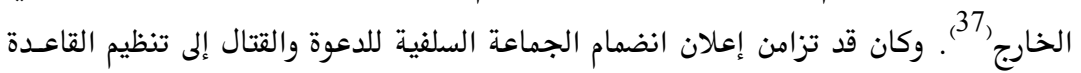
مع عودة رابح كبير، في 17 أيلول/ سبتمبر عام أعلان انفيام لجياعد 2006. 


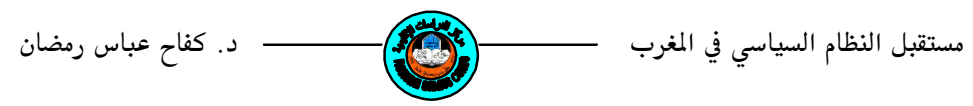

في الوقت نفسه تعهد الرئيس بوتفليقة في 27 أيلول/ سبتمبر 2006 بسحق المتشددين

الإسلاميين مشيرا بذلك إلى عدم احتمال تمديد خطة عفو تستهدف إنهاء سنوات من العنف.

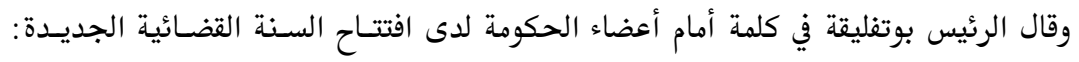

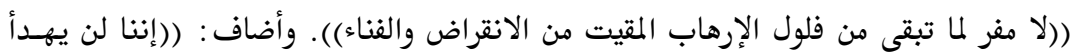

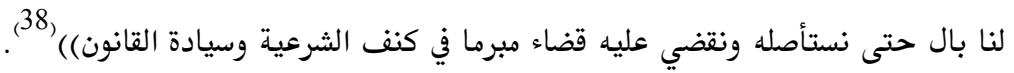

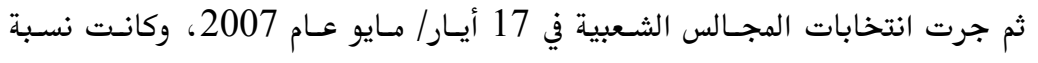

المشاركة لم تتعد (30 \%) ، وتوزعت مقاعد البرلمان الجديد كما يلي : حصلت جبهة التهة التحريسر

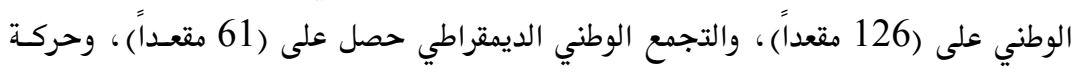

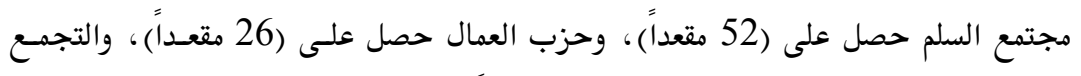

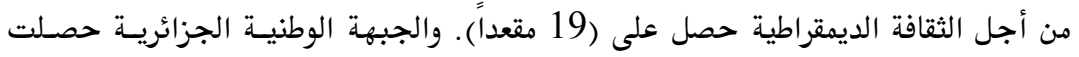

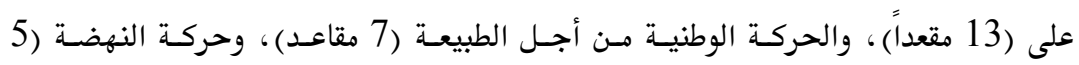

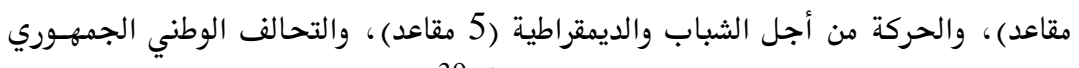
(4 مقاعد)، أخيرا حصل المستقلون على(33 مقعدا) (39).

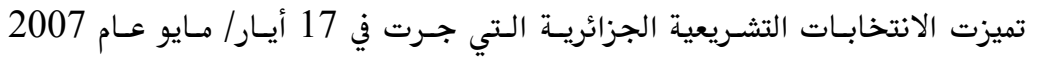

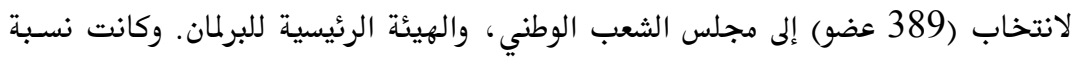

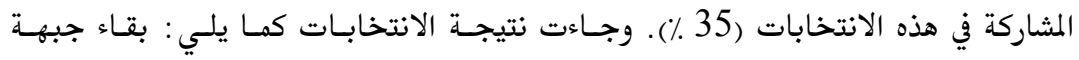

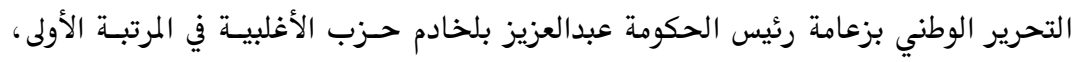

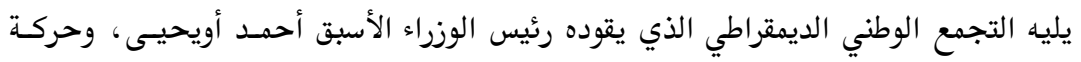

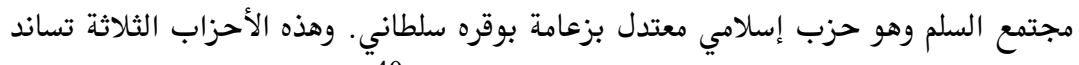
الرئيس بوتفليقة مذذ وصوله إلى سدة الحكم في عام 1999 (40).

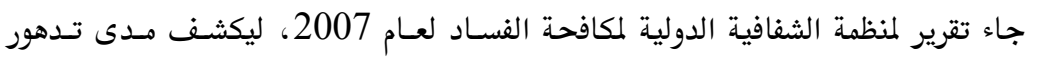

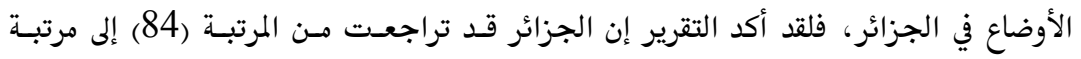
(99)، بعد كولومبيا وغانا(41). مع ذلك أستمر الرئيس بوتفليقة في سياساته الرامية لتحسين الأوضاع في الجزائر، فنـي

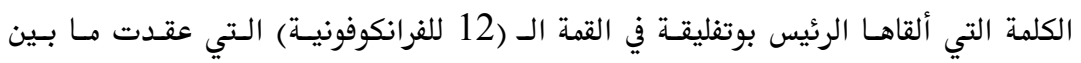


يومي (17- 19 تشرين الأول/ أكتوبر عام 2008) حول موضوع (رشـاد الحكم و التضـامن

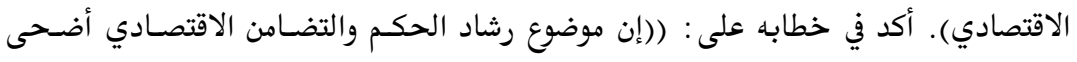

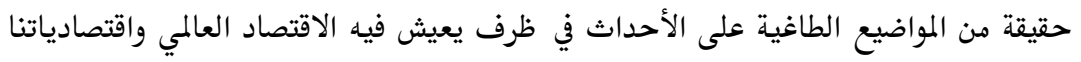

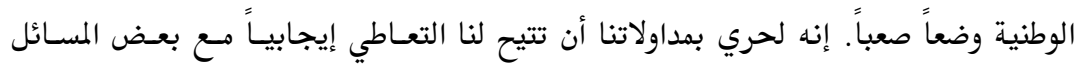

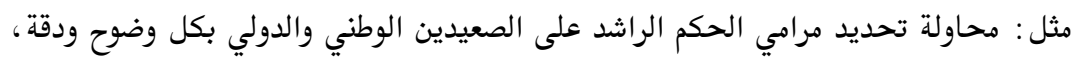

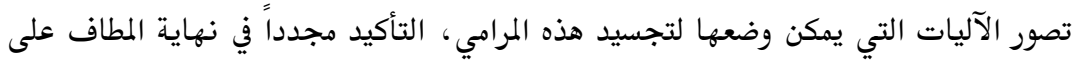

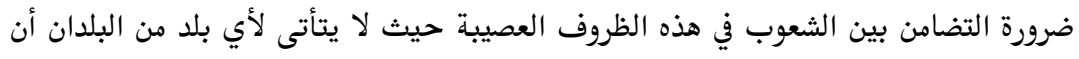
يكون في مأمن من الانعكاسات المترتبة عن العولمة والشمولية)) (42).

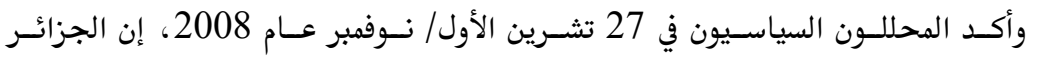

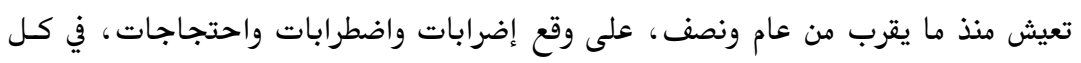

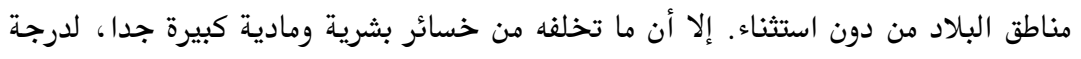

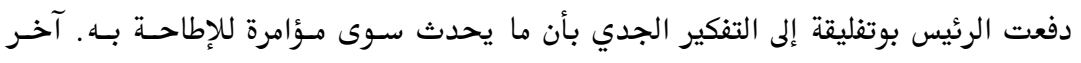

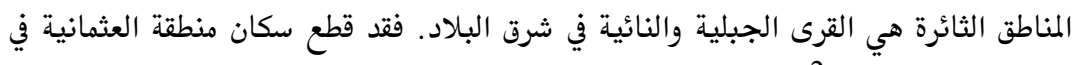

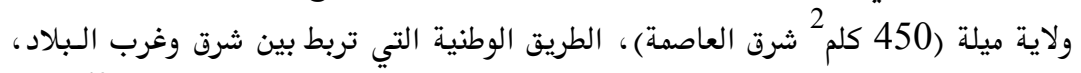

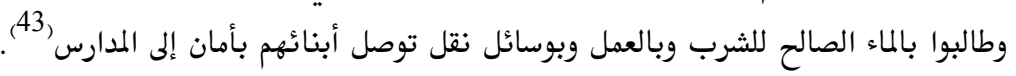

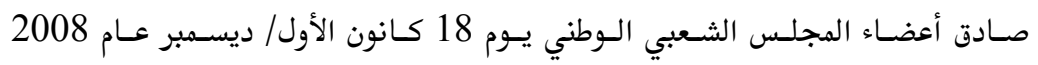

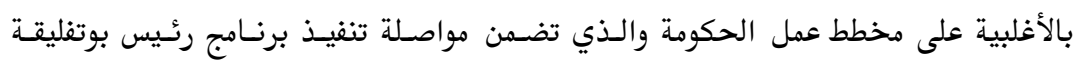

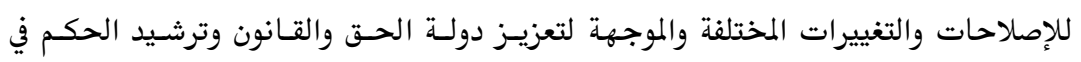

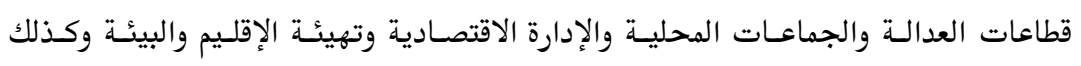

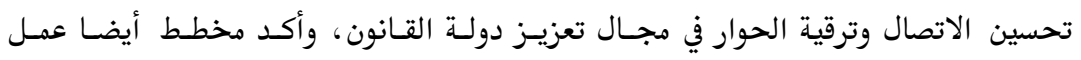

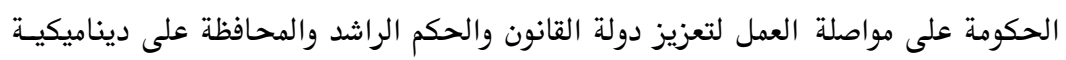

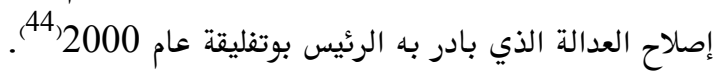

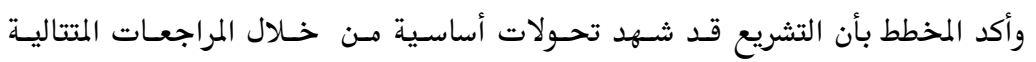

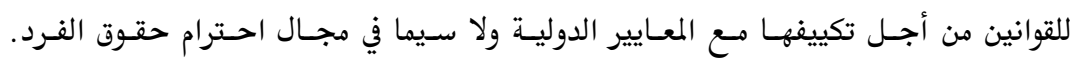




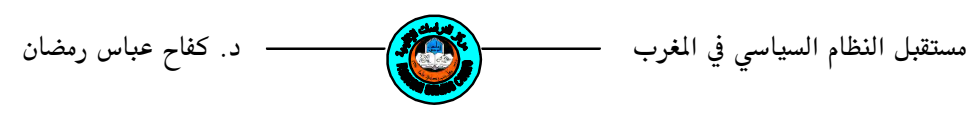

وخصوصاً فيما يتعلق بحفظ النظام العام ومكافحة الأجرام. ومسن جانـب آخـر سـيتم في عـام

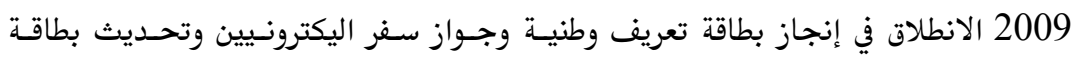

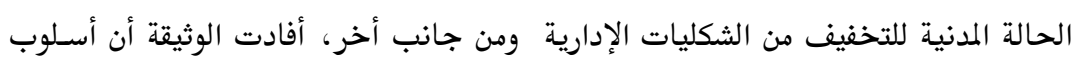

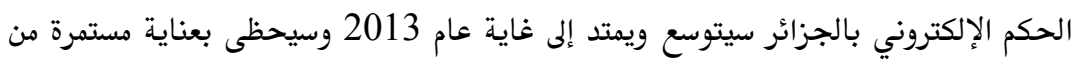

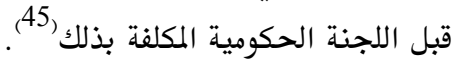

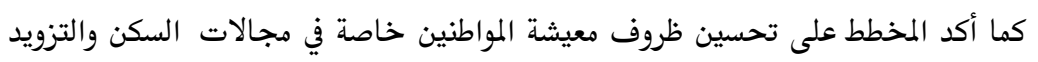

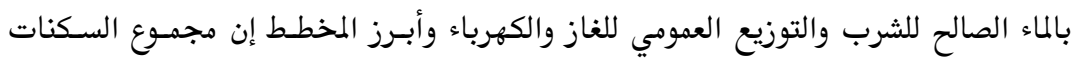

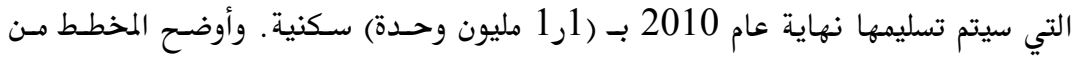

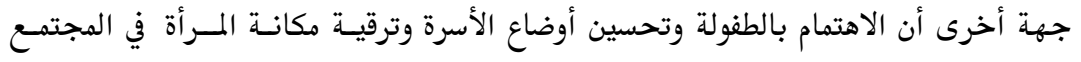
والتشغيل والشباب تعتبر من أهم الخيارات التي ترمي لها السياسة الوطنية للتنمية البشرية

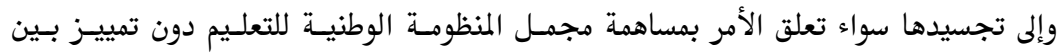

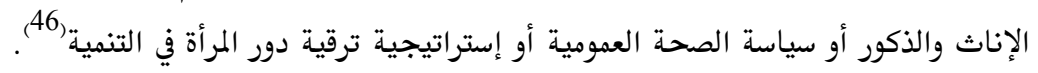
المبحث الثالث: ولاية الرئيس عبدالعزيز بوتفليقة الثالثة (2009-وحتى الآن) جاء في دستور عام 1989، إن: (مدة المهمسة الرئاسـية خمسـة سـنوات. يمكن تجديـد

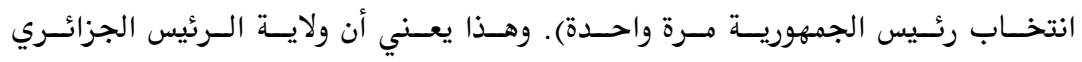

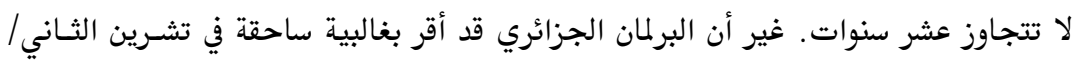
نوفمبر عام 2008 مشروع تعديل الدستور، وهو تغيير سمح بولاية ثالثة لرئيس الجمهوريسة.

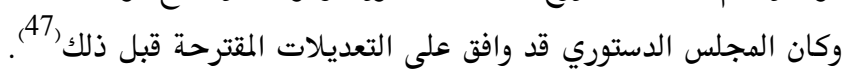

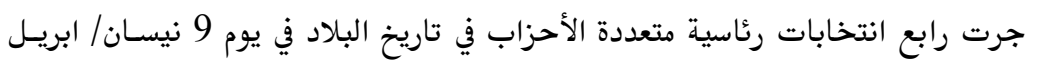

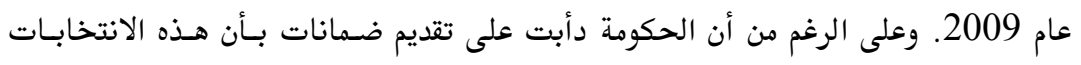

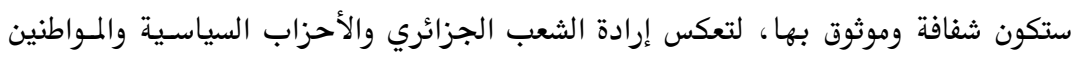

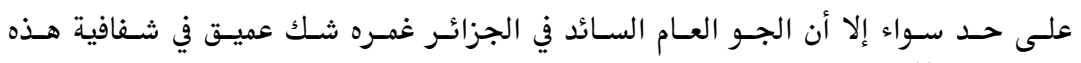
الانتخابات (48). 
انتخب الرئيس بوتفليقة للمرة الثالثة بنسبة (90.24 ٪) من مجموع الأصوات، وحلـت

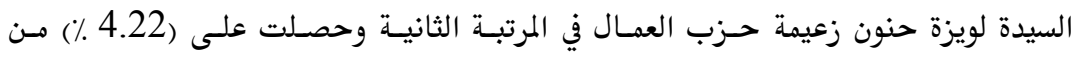

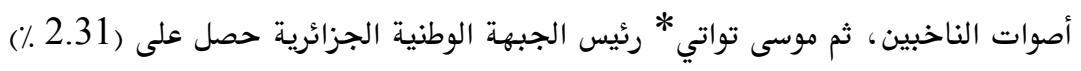

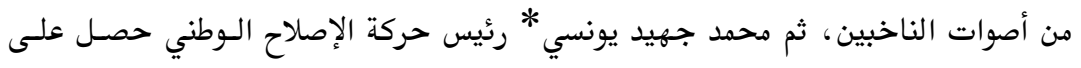

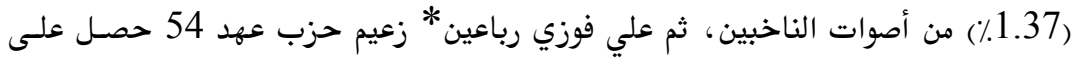

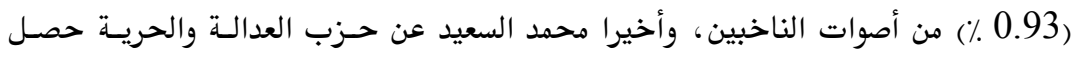

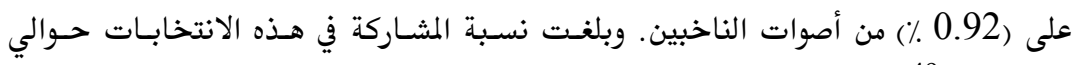
(49) $(\% 74.11)$

لقد تم إنجاز العديد من الأعمال المهمة في إطار الجهود المبذولة في مجال التنمية خـلال

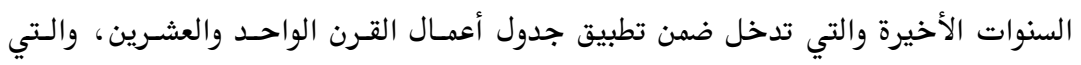

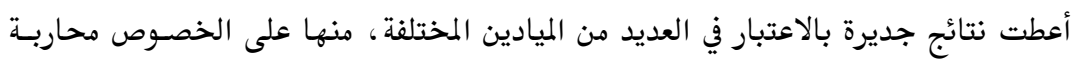

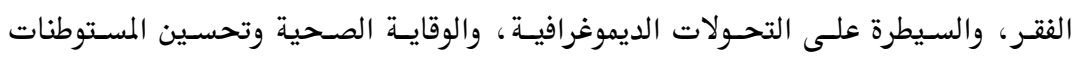

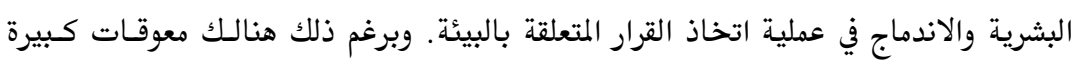

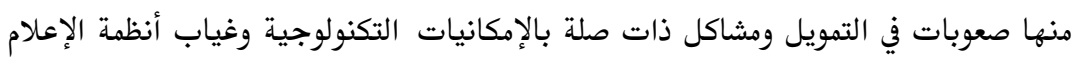

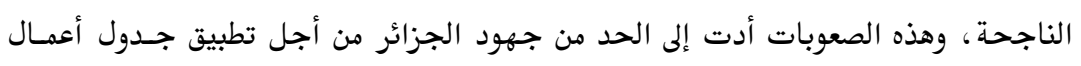
القرن الواحد والعشرين (50). 


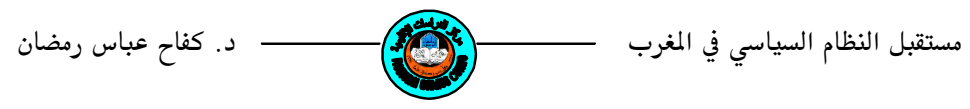

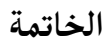

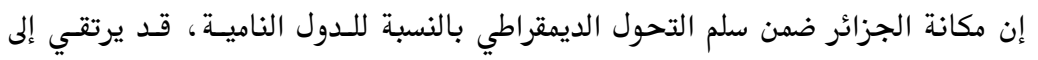

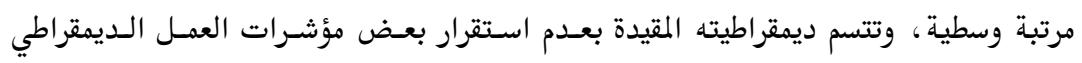

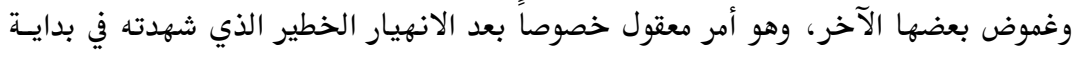
التسعينيات من القرن العشرين المتعددة الأبعاد.

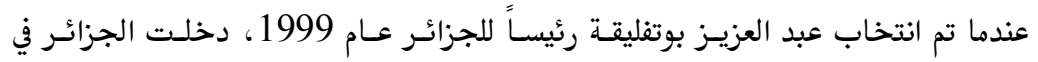

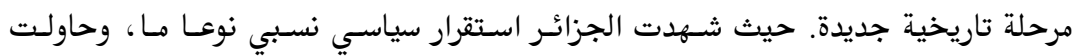

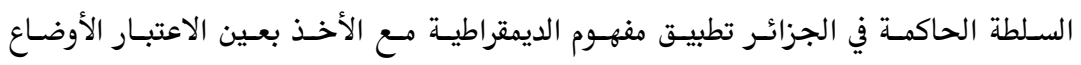

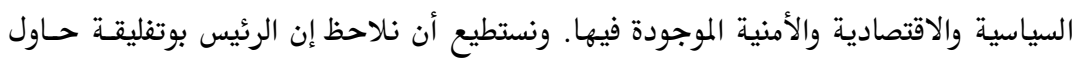

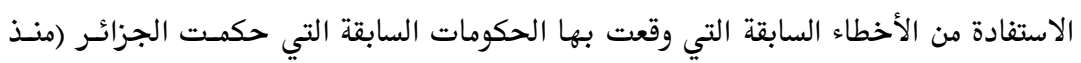

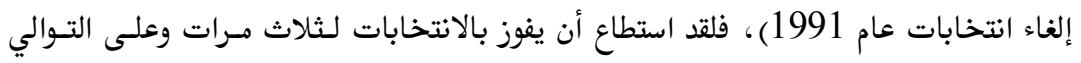

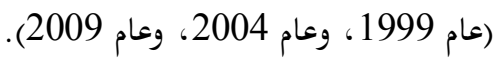
إن الجزائر وغيرها من الدول العربية مطالبة اليوم أكثر مسن أي وقـت مضسى، بمسـايرة

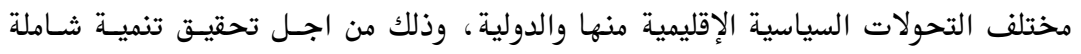

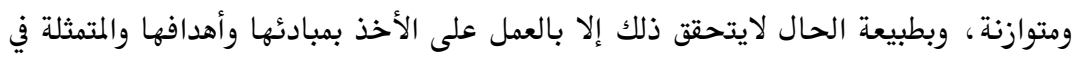

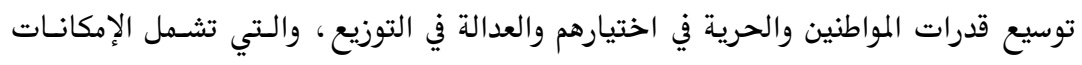

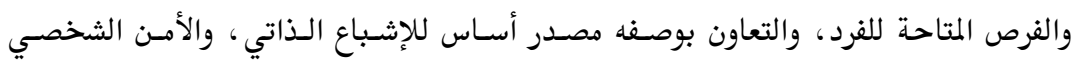

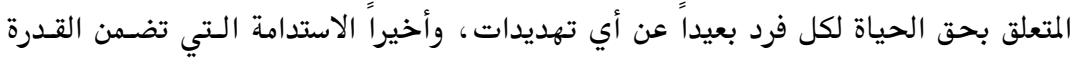

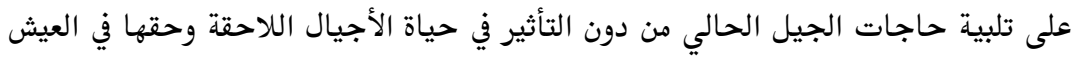

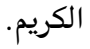
إن هذه المؤشرات لا تلامس النوعية إلا في ظل نظام حكم سـليم للدولـة، والـذي يـرتبط

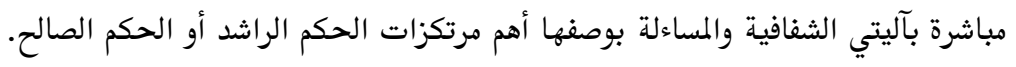




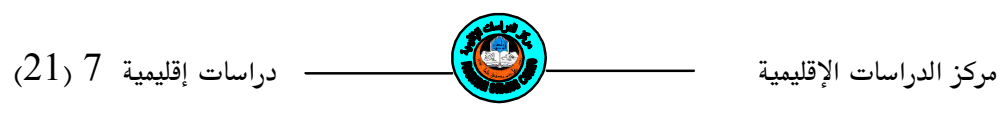

\title{
The Future of Political System in Arab Maghreb: Algeria As An Example
}

\author{
By: Dr. Kifal Allas Ramadan \\ lectures, Historical $\&$ Cultural Dept. Regional Studies Center.
}

\begin{abstract}
Since early 1990's, a state of uncertainty regards the future of political system in Arab Maghreb in the light of current international and regional changes which started with the end of the cold war on international level. With the end of the Gulf war and the rise of Islamic movements in Arab Maghreb on regional level. These changes affect the future of Arab Maghreb in the coming stage.

Algeria is considered a pioneer on third world in general and the Arab Homeland in particular. Thus, we shed light in this paper on the democratic system in Algeria during the reign of president AbdulAziz Botaflika since 1999 till now and this experience has got characteristics and challenges on both internal and external levels.
\end{abstract}




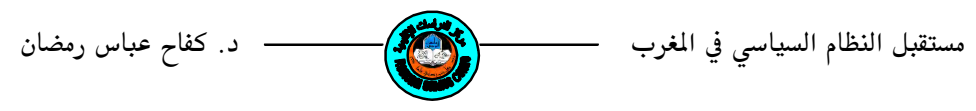

$$
\text { الهوامش والمصادر }
$$

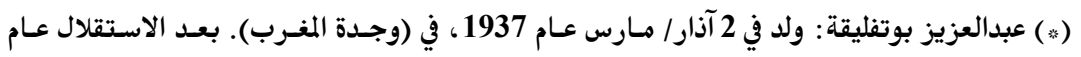

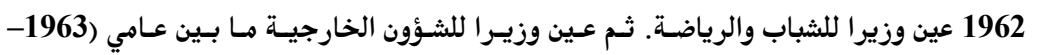

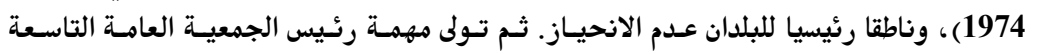

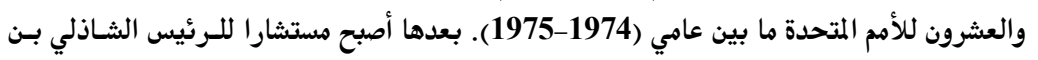

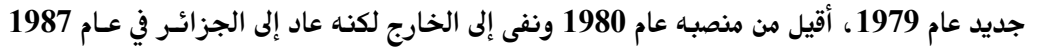

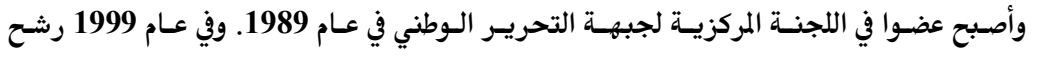

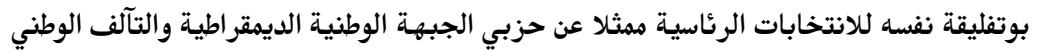

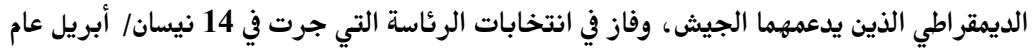

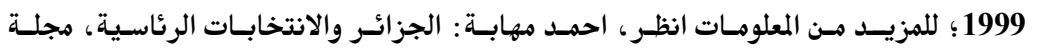

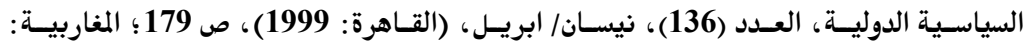

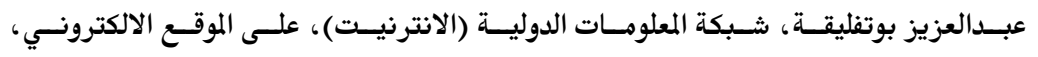


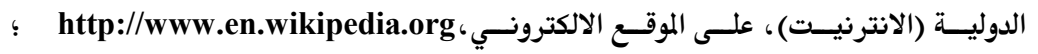

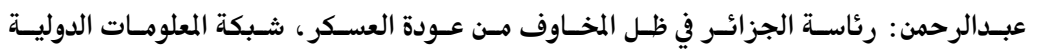

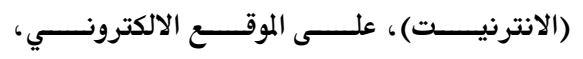
http://www.alarabiya.net

(1) وزارة المجاهدين: أعمال الملتقى الدولي حول الاستعمار بين الحقيقة التاريخية والجدل السياسي،

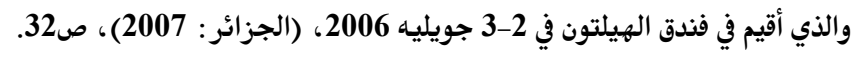

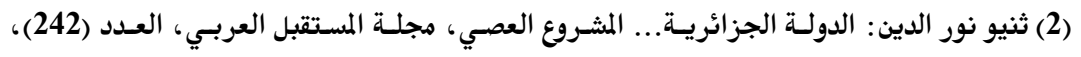

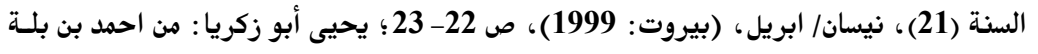

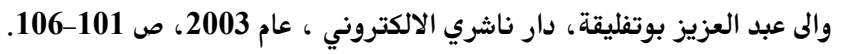

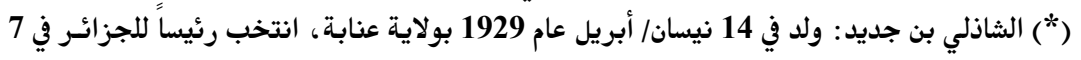

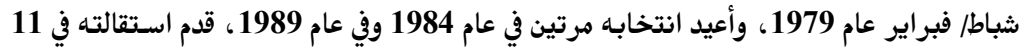

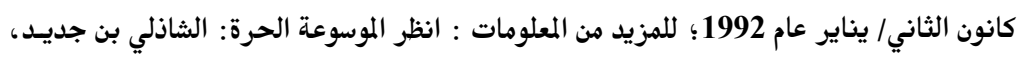

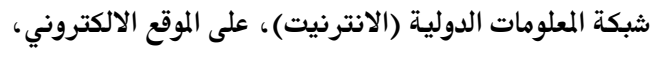
http://www.ar.wikipedia.org

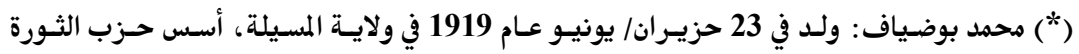

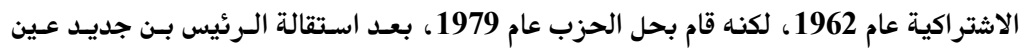

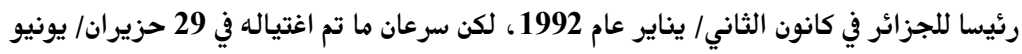




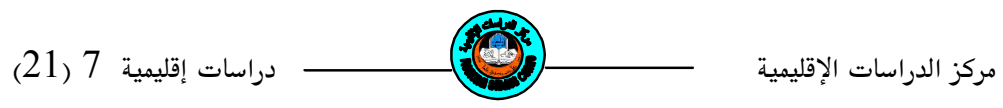

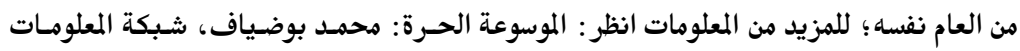

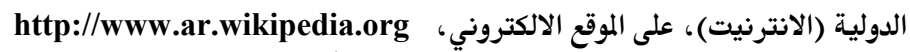

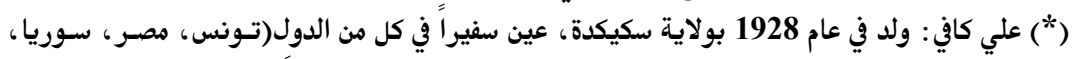

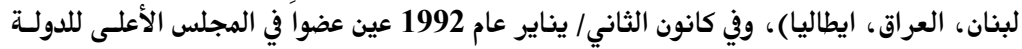

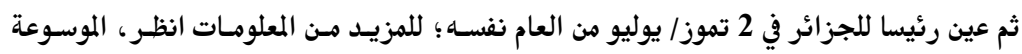

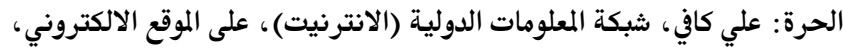

http://www.ar.wikipedia.org

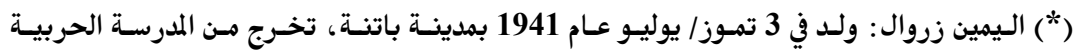

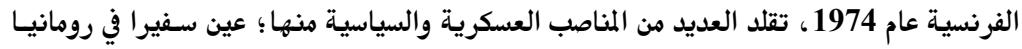

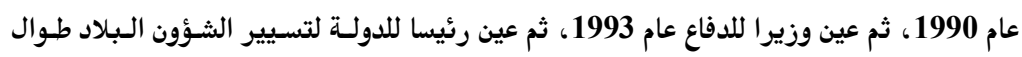

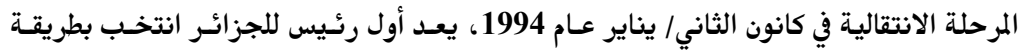

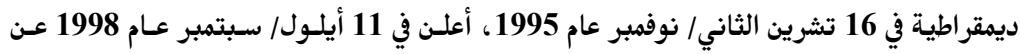

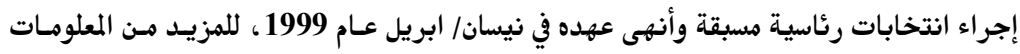

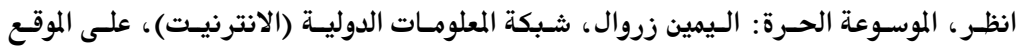

http://www.ar.wikipedia.org

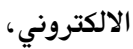

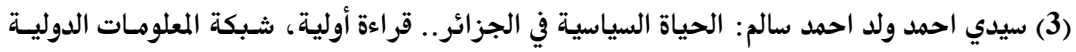

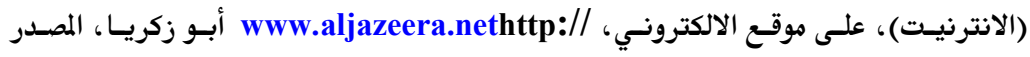

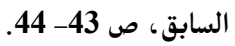

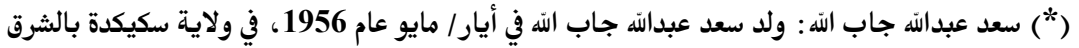

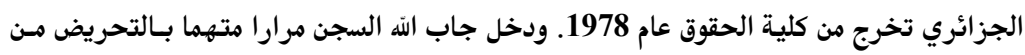

خلال خطبه الدينية الحماسية، فسجن في الأعوام الحئ التاليـة

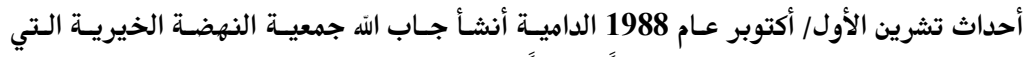

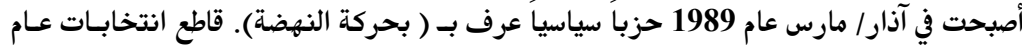

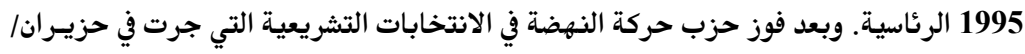

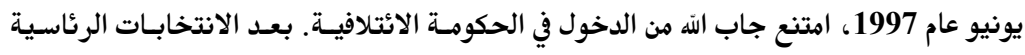

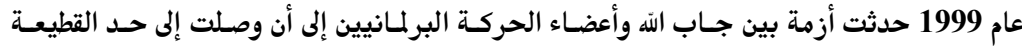

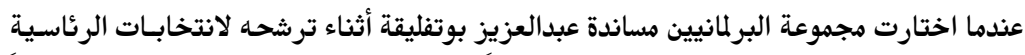

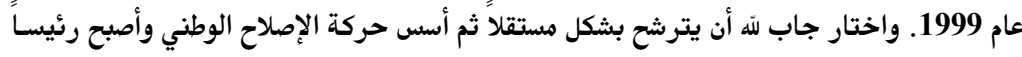

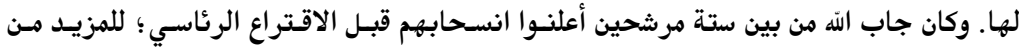




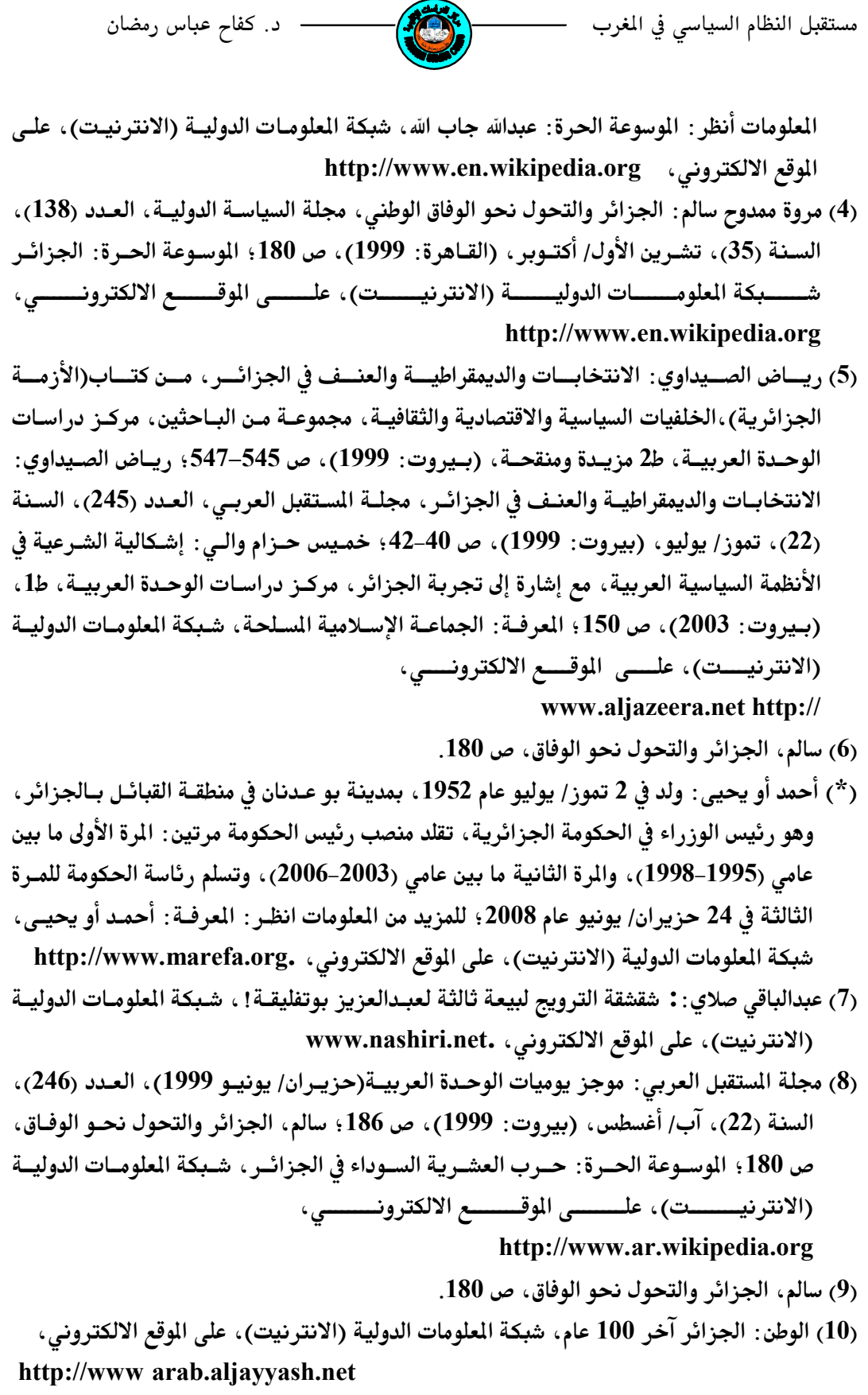


مركز الدراسات الإقليمية

(11) مجلة المستقبل العربي: موجز يوميات الوحدة العربية (أيلول/ سبتمبر 1999)، 1993)، العسد (249)، (249)،

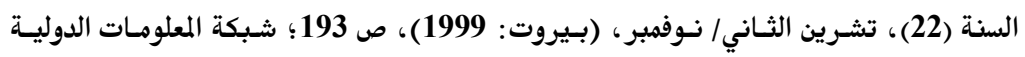

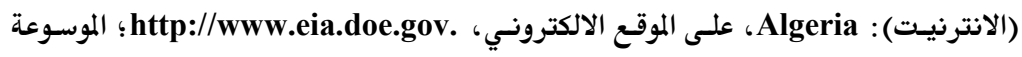

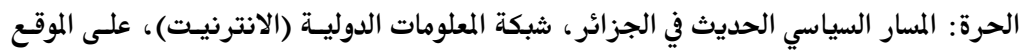

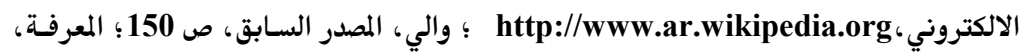

$$
\text { المصدر السابق؛ الوطن، المصدر السابق. }
$$

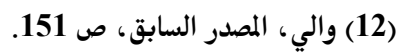

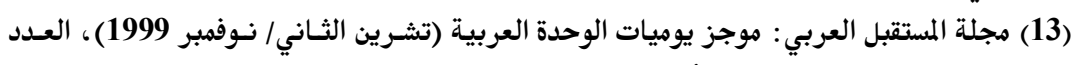

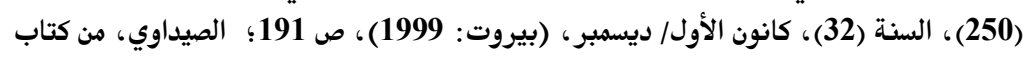

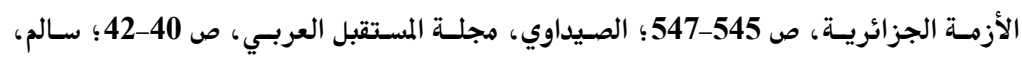

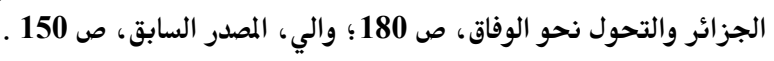

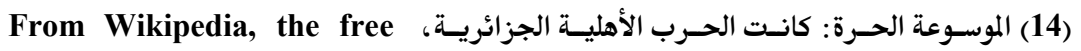

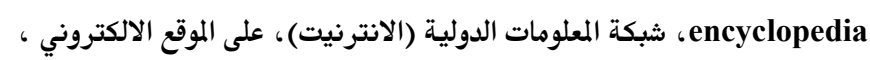

http://www.ar.wikipedia.org

The violence declined substantially, with effective victory for the (15) government.

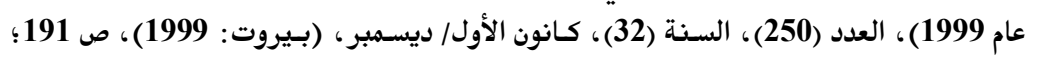

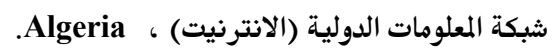

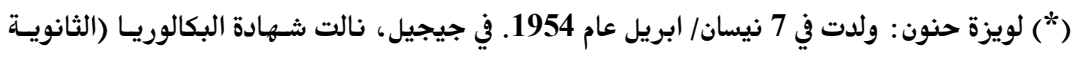

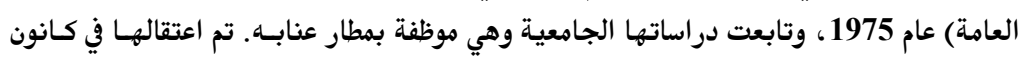

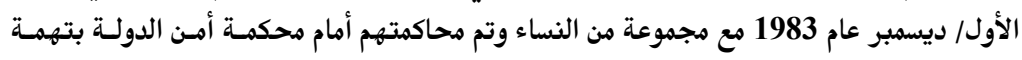

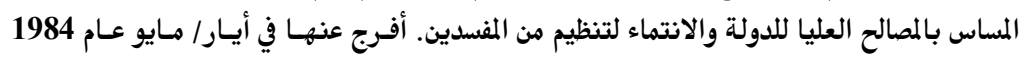

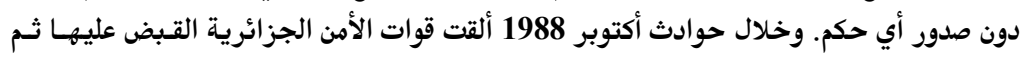

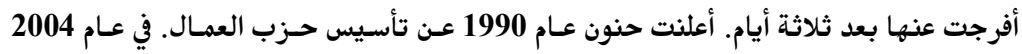

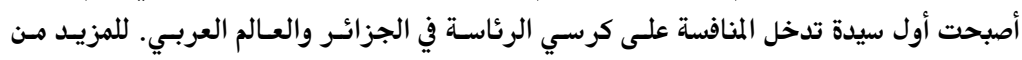

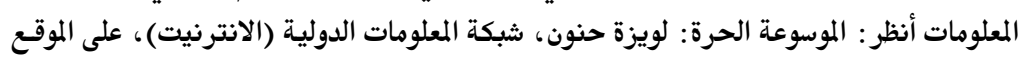

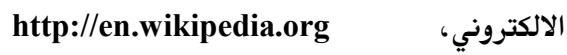

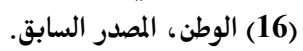

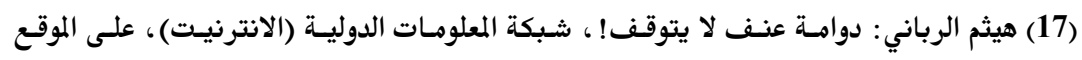
الالكتروني، 


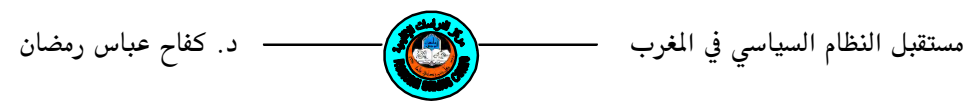

(18) شبكة المعلومات الدولية: انتخابات محلية في الجزائر، شبكة المعلومات الدوليسة (الانترنيـت)،

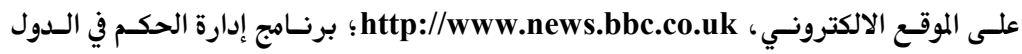

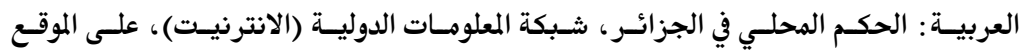

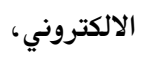

http://undp-pogar.org

(19) هيـثم ربـاني: إضـراب عـام في الجزائر، شـبكة المعلومـات الدوليسة (الانترنيـت)، على الموقع www.swissinfo.ch http://

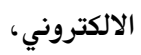

(*) علي بن فليس: سياسي جزائري ولد في 8 أيلـول/ سبتمبر عـام 1944، 1968، في باتنـة شرقي الجزائر.

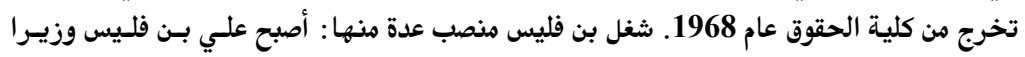

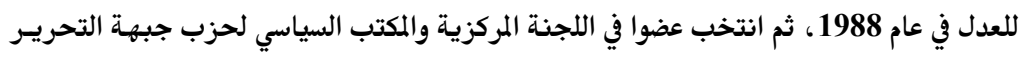

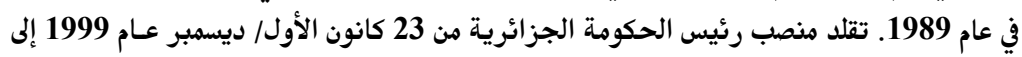

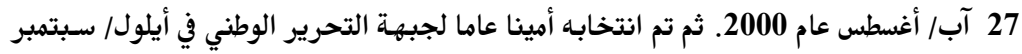

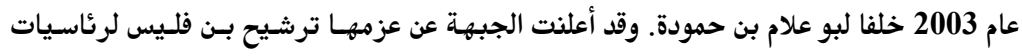

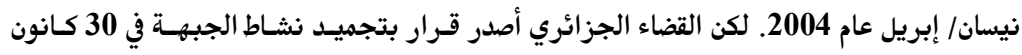

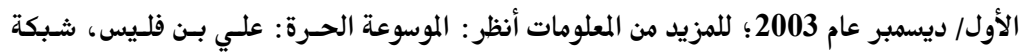

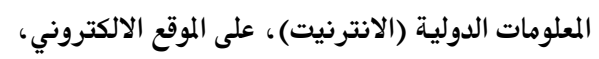

http://en.wikipedia.org

(20) هيثم رباني: بوتفليقة وعقدة جبهة التحرير!، شبكة المعلومات الدولية (الانترنيت)، على الموقع www.swissinfo.chhttp:// الالكتروني،

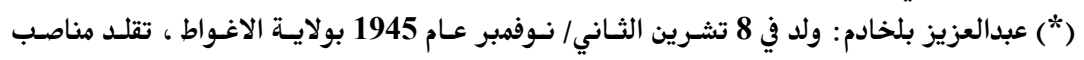

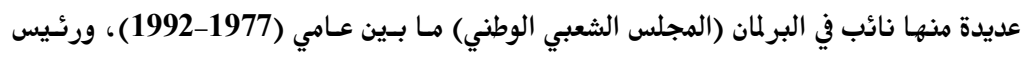

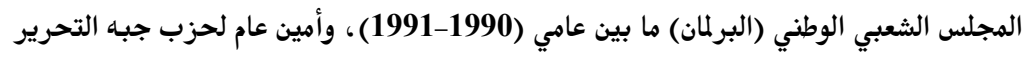

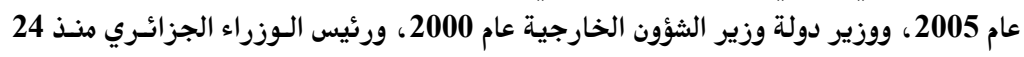

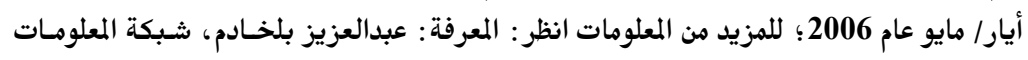

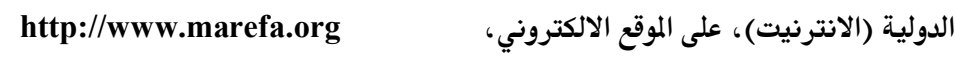




$$
\begin{aligned}
& \text { مركز الدراسات الإقليمية } \\
& \text { (21) هيثم رباني : أزمسة تهـدد كيـان الجزائـر، شـبكة المعلومـات الدوليـة (الانترنيـت)، على الموقـع }
\end{aligned}
$$

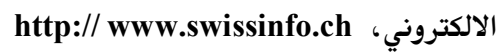

$$
\begin{aligned}
& \text { (22) (23) المصدر نفسه. } \\
& \text { (23) المصدر نفسه. } \\
& \text { (24) المصدر نفسه. } \\
& \text { (25) نسيج الإخبارية: تفاقم الأزمة السياسية في الجزائر، شبكة المعلومات الدولية (الانترنيت)، على المئ }
\end{aligned}
$$

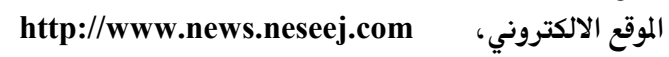

$$
\begin{aligned}
& \text { (26) الموسوعة الحرة، كانت الحرب الأهلية الجزائرية . }
\end{aligned}
$$

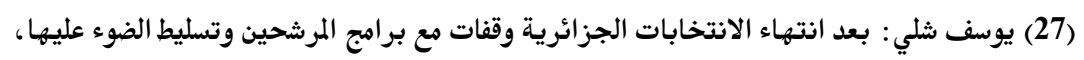

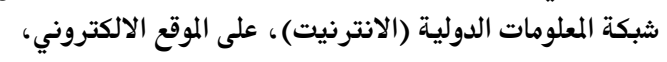

$$
\begin{aligned}
& \text { (29) الموسوعة الحرة، عبدالعزيز بوتفليقة، المصدر السابق. }
\end{aligned}
$$

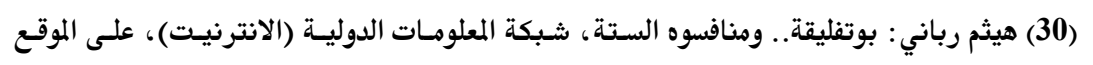

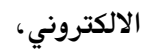

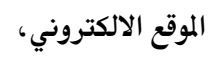




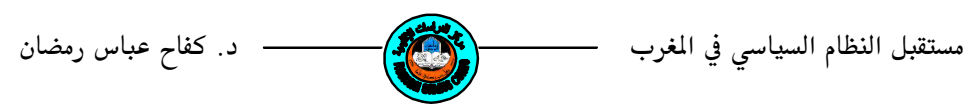

(37) الجزيرة: جبهة الإنقاذ تدعو لمصالحة حقيقية بالجزائر بعد عودة كبير، شبكة المعلومات الدوليسة www.aljazeera.nethttp://

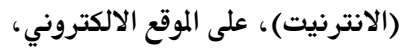

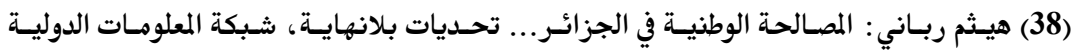

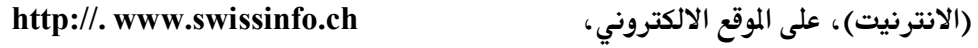

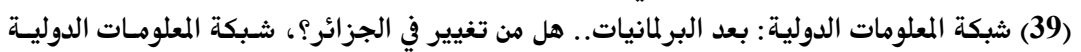

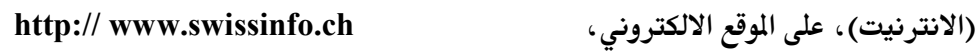

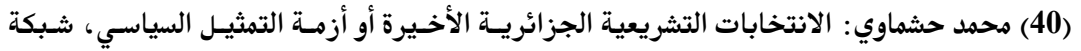

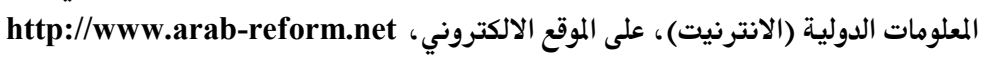

$$
\text { (41) شبكة المعلومات الدولية (الانترنيت) : الجزائر، على الموقع الالكتروني، }
$$

http://www.wikipedai.org.

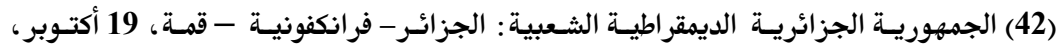

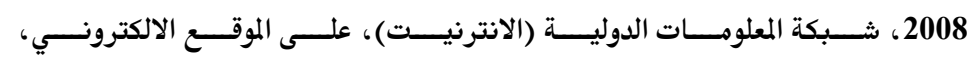

$$
\begin{aligned}
& \text { http://www.elmoudia-dz }
\end{aligned}
$$

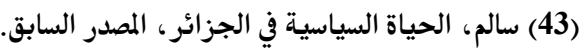

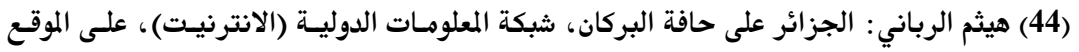

$$
\begin{aligned}
& \text { http:// www.swissinfo.ch }
\end{aligned}
$$

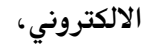

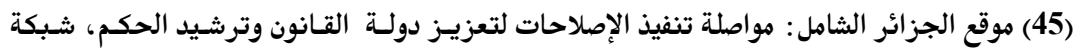

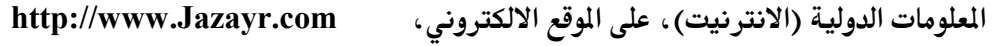

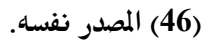

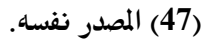

$$
\begin{aligned}
& \text { (48) شبكة المعلومات الدولية (الانترنيت)، الانتخابات الرئاسية - الجزائر نيسـان/ ابريـل } 2009 \text { ، } 27
\end{aligned}
$$

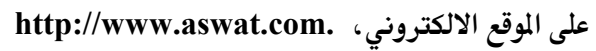

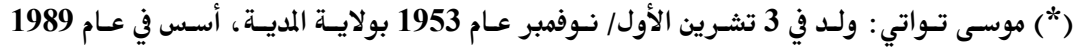

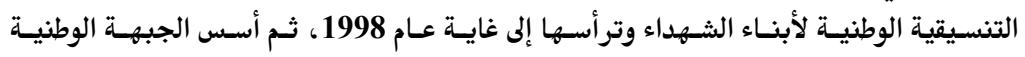

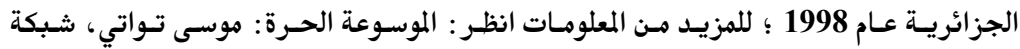

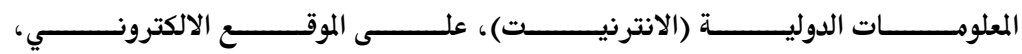

$$
\begin{aligned}
& \text { http://www.ar.wikipedia.erg }
\end{aligned}
$$

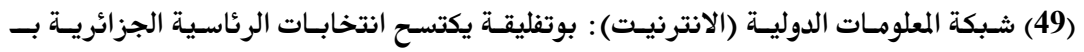

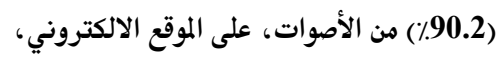


مركز الدراسات الإقليمية

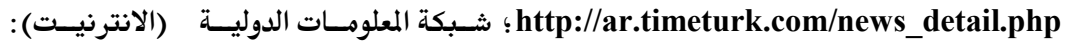

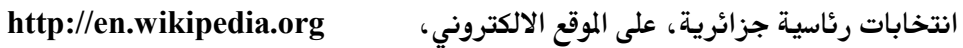

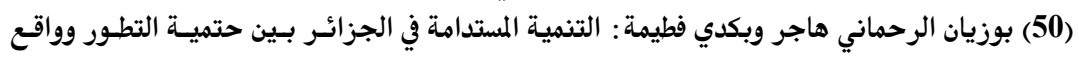

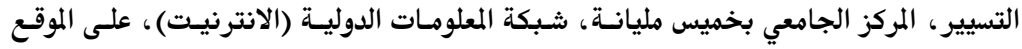

$$
\begin{aligned}
& \text { www.uneca-na.org الالكتروني، }
\end{aligned}
$$

